\title{
La OCDE y los derechos humanos: el caso de las Directrices para Empresas Multinacionales y los Puntos de Contacto Nacional
}

\author{
The OECD and Human Rights: the Case \\ of the Guidelines for Multinational Enterprises \\ and the National Contact Points
}

\section{Humberto Cantú Rivera*}

\begin{abstract}
SUMARIO: I. Introducción. II. Algunos apuntes sobre la Organización para la Cooperación y el Desarrollo Económicos. III. La Declaración de la OCDE de 1976 sobre Inversión Internacional y Empresas Multinacionales, y las Directrices para Empresas Multinacionales. IV. La actualización de 2011 de las Directrices, y la inclusión explícita de los derechos humanos. V. Sobre los Puntos de Contacto Nacional y su misión como instancia de solución de controversias. VI. Breves observaciones respecto a la experiencia mexicana con el Punto de Contacto Nacional de la OCDE. VII. Conclusiones: ¿qué aportan las Directrices de la OCDE a la cuestión de la responsabilidad de las empresas en el ámbito de los derechos humanos? VIII. Bibliografía.
\end{abstract}

* Investigador asociado en el Centro de Investigación en Derechos Humanos (CRDH) y doctorando en Derecho por Université Panthéon-Assas París II (Francia); visitante profesional en la Rama de Procedimientos Especiales de la Oficina del Alto Comisionado de las Naciones Unidas para los Derechos Humanos (Ginebra, 2012); becario de excelencia de la Academia de Derecho Internacional de La Haya (La Haya, 2013); miembro de la International Law Association; becario del CONACYT. Agradezco profundamente a Roel Nieuwenkamp, presidente del Grupo de Trabajo de la OCDE sobre Conducta Empresarial Responsable, por sus pertinentes aclaraciones sobre el tema, así como a la Dirección General de Inversión Extranjera de la Secretaría de Economía, por facilitar el acceso a los documentos relativos al Punto de Contacto Nacional de México.

Artículo recibido el 10 de julio de 2014 Aprobado para publicación el 24 de septiembre de 2014 
Resumen: La Organización para la Cooperación y el Desarrollo Económicos actualizó en 2011 sus Directrices para Empresas Multinacionales, con la finalidad de añadir un capítulo referente a los derechos humanos y hacer más eficiente su mecanismo de implementación, los Puntos de Contacto Nacional. Estas modificaciones alinean el instrumento de la OCDE con los Principios Rectores sobre Empresas y Derechos Humanos de la ONU, adoptados también en 2011, y ayudan a crear una sinergia y convergencia a nivel internacional respecto a los estándares existentes sobre la responsabilidad de las empresas en materia de derechos humanos. Constituyen un elemento importante en este ámbito, y contribuyen al desarrollo de una cultura de conducta empresarial responsable.

Palabras clave: OCDE, Directrices para Empresas Multinacionales, Puntos de Contacto Nacional, Principios Rectores de la ONU sobre empresas y derechos humanos, derechos humanos.

ABSTRACT: The Organization for Economic Co-operation and Development updated its Guidelines for Multinational Enterprises in 2011, adding a human rights chapter and bolstering its implementation mechanism, the National Contact Points. These changes align the OECD instrument with the UN Guiding Principles on Business \& Human Rights, also adopted in 2011, and help to create a synergy and convergence at the international level regarding standards on corporate responsibility for human rights. They constitute an important element in the field of business and human rights, and contribute to the development of a culture of responsible business conduct.

Key words: OECD, Guidelines for Multinational Enterprises, National Contact Points, UN Guiding Principles on Business \& Human Rights, human rights.

RÉSUMÉ: L'Organisation de Coopération et de Développement Économiques a mis à jour les Principes directeurs à l'intention des entreprises multinationales en 2011, en ajoutant un nouveau chapitre sur les droits de l'homme et en renforçant les Points de contact nationaux, leur mécanisme de mise en oeuvre. Ces changements alignent l'instrument de l'OCDE aux Principes directeurs des Nations unies sur les entreprises et les droits de l'homme, adoptés aussi en 2011, et aident à creer une synergie et une convergence au niveau international par rapport aux standards applicables aux entreprises dans la matière. Ils constituent un élément important dans le champ des entreprises et droits de l'homme, et contribuent au développement d'une culture de conduite responsable des entreprises.

Mots-clés: OCDE, Principes directeurs à l'intention des entreprises multinationales, Points de contact nationaux, Principes directeurs des Nations unies sur les entreprises et les droits de l'home, droits de l'homme. 


\section{INTRODUCCIÓN}

La responsabilidad de las empresas en el ámbito de los derechos humanos es un tema que ha recibido una cantidad significativa de atención en la última década, particularmente en relación con el mandato en la Organización de las Naciones Unidas que culminó con la adopción de los Principios Rectores sobre Empresas y Derechos Humanos en 2011. Iniciativas regionales y nacionales de implementación de estos principios de las Naciones Unidas se encuentran en desarrollo, particularmente en Europa, y nuevos desafíos aparecen en el horizonte a nivel internacional.

Sin embargo, una iniciativa que ha recibido una atención considerablemente menor son las Directrices de la OCDE para Empresas Multinacionales. A pesar de no ser una nueva iniciativa - figuran en el escenario internacional desde 1976-, fueron revisadas por última vez en 2011, y adaptadas a la nueva constelación de instrumentos internacionales que se refieren a la responsabilidad de las empresas de, por lo menos, respetar los derechos humanos en el marco de sus actividades y operaciones. En este sentido, las Directrices contienen recomendaciones sobre derechos humanos en uno de sus capítulos, mientras que tratan otros temas como las relaciones laborales, el medio ambiente o la corrupción, en otros. Así, constituyen un marco de referencia más amplio que el propuesto por el mandato de la ONU en 2011, concentrado exclusivamente en el impacto en los derechos humanos.

Este tema es de particular importancia para México, por dos motivos esenciales: en primer lugar, México continúa siendo un receptor importante de inversión extranjera directa en América Latina, ${ }^{1}$ por lo que la presencia de empresas multinacionales en el país es constante. En vista de ello, es importante encontrar un balance efectivo entre la generación de desarrollo económico y el respeto a los derechos humanos, con el objetivo de que la

1 Según el último Informe Mundial de Inversión, México y Brasil continúan siendo las dos mayores economías del subcontinente latinoamericano. UNCTAD, World Investment Report 2014, p. 63: "In Brazil and Mexico - the two biggest economies, where the region's FDI to the manufacturing sector is concentrated - FDI is driven by two different strategies; export-oriented in Mexico (efficiency-seeking) and domestic-market-oriented in Brazil (market-seeking)". 
inversión extranjera directa en México no solo produzca riqueza económica, sino que contribuya a la mejora de las condiciones sociales en el país. En segundo lugar, México es uno de los Estados miembros de la Organización para la Cooperación y el Desarrollo Económicos, por tanto, una cantidad importante de tratados internacionales, convenciones y declaraciones son en principio aplicables para el Estado mexicano. Dentro de ellas se encuentra la Declaración sobre Inversión Internacional y Empresas Multinacionales, de la que las Directrices de la OCDE para Empresas Multinacionales son parte. Por ello, es importante tener consciencia del contenido de este instrumento, el funcionamiento de su mecanismo y los objetivos que su implementación persigue.

Este artículo busca presentar de manera sucinta el desarrollo y contenido de las Directrices de la OCDE para Empresas Multinacionales, así como el funcionamiento y algunas experiencias de su mecanismo de implementación. A comparación de otros instrumentos internacionales, como el descrito anteriormente de las Naciones Unidas, estas Directrices han recibido poca atención por parte de la comunidad jurídica a nivel internacional, y ciertamente en México han existido escasas referencias académicas sobre su funcionamiento; ${ }^{2}$ en vista de lo anterior, se considera pertinente abordar este tema. Tras esta breve introducción, el artículo presenta en su segunda sección algunas breves referencias al origen de la Organización para la Cooperación y el Desarrollo Económicos y el ingreso de México a la misma; una tercera sección hace referencia al origen de las Directrices para Empresas Multinacionales en 1976, haciendo algunos apuntes sobre los cambios de los que fueron objeto en diversas revisiones, hasta llegar a la penúltima revisión, del año 2000.

Posteriormente, el cuarto apartado se centra en examinar la revisión del año 2011, que de cierta forma fue una revisión integral de las Directrices, con el objeto de reflejar los principales cambios en el escenario internacional de las inversiones; una quinta sección hace referencia a los Puntos de Contacto Nacional, el mecanismo de implementación de las Directrices, revisando algunos de los cambios principales que ha sufrido desde su aparición en 1984 y su consolidación a partir del año 2000, incluyendo los más recientes en la revisión de 2011. Antes de presentar algunas conclusiones generales sobre el aporte que hacen las Directrices al tema de la responsa-

Incluso reciben poca difusión por parte del Gobierno mexicano, a pesar del compromiso adquirido en el marco de la OCDE. 
bilidad de las empresas en materia de derechos humanos, se hacen algunos breves comentarios sobre los casos que han sido presentados ante el Punto de Contacto Nacional de México, para tratar de analizar algunas de las características y patrones que han estado presentes en la actuación de este mecanismo. De esta manera, el artículo intenta presentar de forma breve esta interesante e importante faceta en el tema de los derechos humanos y las empresas.

\section{AlgunOS APUNTES SOBRE LA ORGANIZACIÓN PARA LA COOPERACIÓN Y EL DESARROLLO ECONÓMICOS}

La Organización para la Cooperación y el Desarrollo Económicos (OCDE) fue creada en 1960, como resultado del tratado internacional ${ }^{3}$ acordado para reconstituir a la Organización para la Cooperación Económica Europea (OCEE), que había estado a cargo de ejecutar el Plan Marshall, tras la Segunda Guerra Mundial, para la reconstrucción de Europa. El 14 de diciembre de 1960, los Estados Unidos de América y Canadá determinaron unirse a los miembros de la OCEE y establecer una nueva organización internacional, la OCDE, cuyo objetivo sería la promoción de políticas destinadas a lograr el mayor crecimiento económico y de generación de empleos posible, así como la mejora del nivel de vida, en sus países miembros, de una manera sustentable que permitiera mantener una estabilidad financiera y contribuir al desarrollo de la economía mundial; ${ }^{4}$ contribuir a una expansión y desarrollo económicos saludables en los distintos países del mundo, independientemente de su carácter como miembros de la organización, ${ }^{5}$ y contribuir a la expansión multilateral y equitativa del comercio internacional. ${ }^{6}$ La entrada en vigor de la Convención tuvo lugar el 30 de septiembre de 1961, conforme a lo estipulado por su artículo 14.3, con lo cual formalmente nació la OCDE, señalándose como su sede princi-

3 Convención sobre la Organización para la Cooperación y el Desarrollo Económicos (14 de diciembre de 1960), Preámbulo.

4 Ibidem, artículo 1.a).

5 Ibidem, artículo 1.b).

6 Ibidem, artículo 1.c). 
pal la ciudad de París ${ }^{7}$ — actualmente en el Château de la Muette - y como depositario de los instrumentos de ratificación o aceptación del gobierno francés. ${ }^{8}$

A los 20 Estados miembros originales en 1960, se han añadido 14 nuevos países, contando en la actualidad esta organización con 34 Estados miembros, aunque se analiza la entrada de otros cinco países, dentro de los que se encuentran Rusia y Colombia. La principal intención de la organización es la definición de políticas económicas y sociales a nivel internacional que coadyuven al desarrollo de los diferentes países del mundo. ${ }^{9}$ Siendo una organización intergubernamental, tiene como misión la identificación de soluciones a problemas comunes en las diferentes regiones del planeta y a nivel internacional, con la intención de generar crecimiento sostenido a nivel mundial; no obstante, no solo participan en la definición de tales políticas sus Estados miembros, sino que además trabaja de cerca con dos comités asesores - uno representando a la industria y los negocios, otro a los sindicatos y organizaciones de trabajadores-, con la finalidad de diseñar políticas públicas internacionales que ayuden al desarrollo de una sociedad internacional abierta y justa.

Si bien su compromiso principal es con el mantenimiento y expansión de las economías de mercado, apoyadas por instituciones democráticas y concentradas en el bienestar de los ciudadanos, la labor de la OCDE cubre diferentes áreas que no se limitan exclusivamente a aspectos económicos. De tal forma, su trabajo incluye acciones en áreas como la gobernanza, la lucha contra la corrupción, la responsabilidad empresarial, la educación, la salud, el desarrollo, la inversión internacional, los impuestos o el medio

7 Ibidem, artículo 18.

8 Ibidem, artículo 14.2

9 Herdegen, M., Principles of International Economic Law, Oxford, Oxford University Press, 2013, p. 32: “The Organization for Economic Cooperation and Development (OECD) was established as a forum for cooperation for Western industrialized countries and now includes important emerging countries (such as Mexico, Chile and Turkey). In the near future, Russia will also join. By coordinating the economic and monetary policies of its members, the OECD has gained significant importance. Additionally, the OECD supports the economic development of developing countries through its Development Assistance Committee which comprises 24 OECD Member States as well as the European Commission. The World Bank, the IMF, and the United Nations Development Programme (UNDP) participate as observers". 
ambiente, fomentando la cooperación, el diálogo, el consenso y la revisión por pares. ${ }^{10}$

México es un Estado miembro de la OCDE desde mayo de 1994, y es uno de los dos países de América Latina que tienen tal calidad en la organización (siendo el otro miembro la república chilena). Como uno de los principales receptores de inversión extranjera directa en el continente y gracias a su política neoliberal desde la década de 1980, su identificación como un país "en vías de desarrollo" lo colocaría en una situación privilegiada al poder discutir sobre políticas de desarrollo económico y social con otros Estados industrializados en este foro, cuyas empresas han tradicionalmente establecido subsidiarias y sus operaciones en el país. Lo anterior resulta de especial importancia si se toma en cuenta el énfasis que se ha hecho a nivel internacional sobre la actuación de las empresas transnacionales, usualmente provenientes de países industrializados, en sus operaciones en países en vías de desarrollo. También resulta trascendente al considerar que México ya no solo recibe inversión extranjera directa, sino que también la exporta, a través de las operaciones de distintas multinacionales, como inter alia Cemex, Televisa, Grupo Alfa o América Móvil. En virtud de ello, es pertinente analizar el desarrollo que sobre esta cuestión ha tenido lugar en el seno de la OCDE, desde 1976 a la fecha, para tratar de visualizar el potencial efecto que tales iniciativas internacionales podrían generar en México.

\section{LA DECLARACIÓN DE LA OCDE DE 1976 SOBRE INVERSIÓN INTERNACIONAL Y EMPRESAS MULTINACIONALES, Y LAS DIRECTRICES PARA EMPRESAS MULTINACIONALES}

Una consideración importante que debe tenerse en cuenta al examinar el desarrollo de las preocupaciones extra-económicas de la OCDE es el contexto histórico y geopolítico en que éstas se dieron. Las décadas de 1960 y 1970 vieron la aparición de nuevos Estados con amplios recursos naturales, pero con una limitada participación en la política y economía internaciona-

10 Para una visión detallada sobre la labor y áreas de trabajo de la OCDE, véase OCDE, Secretary-General's Report to Ministers, París, OCDE, 2014, pp. 54-63. 
les. En razón de ello, hubo una llamada a desarrollar un nuevo orden económico internacional en el que se incluyera la participación de los nuevos países independientes, particularmente en el seno de la Organización de las Naciones Unidas. ${ }^{11}$

Asimismo, se buscó limitar y regular dentro de esa discusión las actividades de las empresas transnacionales, ${ }^{12}$ con la finalidad de proteger las economías de los países en donde éstas operaban, ${ }^{13}$ en su mayoría países en vías de desarrollo. ${ }^{14}$ Así, en 1974 apareció en el seno de la ONU una iniciativa para desarrollar un código de conducta para empresas transnacionales, ${ }^{15}$

11 Asamblea General, Declaración sobre el establecimiento de un nuevo orden económico internacional, A/RES/S-6/3201 (1o. de mayo de 1974)

12 Algunos estudios contemporáneos a esa época se enfocaban ya a esas cuestiones. Véase por ejemplo Fajnzylber, F. y Martínez Tarragó, T., Las empresas transnacionales: Expansión a nivel mundial y proyección en la industria mexicana, México, FCE, 1974, pp. 26 y 27: "Recientemente, sin embargo, ha habido una toma de conciencia por parte de los países receptores, sean o no a su vez países de origen de la inversión extranjera, motivada por el conocimiento de que el poder que han adquirido las mismas atenta contra la autonomía económica y política de las naciones, y que sus sistemas de operación escapan al control del país de destino, sino inclusive del país de origen”. Véase también Sepúlveda Amor, B. et al., Las empresas transnacionales en México, México, El Colegio de México, 1974.

13 Véase Rasche, A., "The United Nations and TNCs: How the UN Global Compact Has Changed The Debate", en Lawrence, J. y Beamish, P. (eds.), Globally Responsible Leadership: Managing According to the UN Global Compact, Thousand Oaks, Sage, 2013, p. 34: "As the reach of TNCs gained momentum throughout the late 1960s and early 1970s, the UN started to look into their social and economic impact on nations, particularly the developing world. At this time, the UN saw the existence of TNCs largely as a reason for concern, mostly because cross-border economic activities were believed to disadvantage host countries (in many cases developing nations)". Véase también Keller, H., "Corporate Codes of Conduct and their Implementation: The Question of Legitimacy”, en Wolfrum, R. y Röben, V. (eds.), Legitimacy in International Law, Berlín, Springer, 2008, p. 227.

14 Asamblea General, Declaración sobre el establecimiento de un nuevo orden económico internacional, A/RES/S-6/3201 (1o. de mayo de 1974), párr. 4.g.: "Regulación y supervisión de las actividades de las corporaciones transnacionales a través de la adopción de medidas en favor de las economías nacionales de los países donde tales corporaciones transnacionales operan, basadas en la completa soberanía de esos países”. Sobre el Código de Conducta de la ONU para Empresas Transnacionales, véase también Cantú Rivera, H. F., "Empresas y derechos humanos: ¿hacia una regulación jurídica efectiva, o el mantenimiento del status quo?", Anuario Mexicano de Derecho Internacional, vol. XIII, 2013, pp. 316-319.

15 Véanse Muchlinski, P. T., Multinational Enterprises \& The Law, 2a. ed., Oxford, Oxford University Press, 2007, pp. 660-662, y Newcombe, A. y Paradell, L., Law and Practice of Investment Treaties, Alphen aan den Rijn, Kluwer Law International, 2009, p. 33, quien 
que estableciera obligaciones derivadas del derecho internacional y un mecanismo de supervisión. El Proyecto de Código de Conducta para Empresas Transnacionales ${ }^{16}$ dividido en tres secciones principales y cuya última versión data de 1990, contemplaba imponer ciertas obligaciones a las actividades de las empresas transnacionales, establecer reglas generales para el trato que éstas debían recibir en los Estados donde operaran, así como las medidas a adoptar para la implementación del Código de Conducta, tanto a nivel nacional como internacional. Sin embargo, la división ideológica entre los países industrializados y los países en vías de desarrollo, así como la falta de consenso y la imposibilidad de concretar acuerdos en una cantidad importante de temas, llevaron al abandono del proyecto en 1992. ${ }^{17}$ No obstante ello, al mismo tiempo que comenzaba el debate en el seno de las Naciones Unidas en torno al Código de Conducta para Empresas Transnacionales, los miembros de la OCDE iniciaron un proceso propio en ese frente. ${ }^{18}$

En 1976, la OCDE adoptó la Declaración sobre Inversión Internacional y Empresas Multinacionales, ${ }^{19}$ un compromiso político de los Estados parte de la OCDE para mejorar el ámbito de las inversiones, alentar la contribución de las empresas multinacionales al progreso económico y social, y reducir y resolver las dificultades que surgieran como resultado de sus operaciones. La Declaración se encuentra conformada por cuatro elementos (las Directrices para Empresas Multinacionales, el Trato Nacional,

hace breves referencias al Proyecto de Código de Conducta de la ONU sobre Corporaciones Transnacionales, y a las Directrices de la OCDE para Empresas Multinacionales.

16 Consejo Económico y Social, Proyecto de código de conducta para empresas transnacionales, E/1990/94 (21 de mayo de 1990).

17 Feeney, P., "Empresas y derechos humanos: La lucha por la rendición de cuentas en la ONU y el rumbo futuro de la agenda de incidencia”, SUR-Revista Internacional de Derechos Humanos, vol. 6, núm. 11, 2009, p. 178: “...el proceso de elaboración de este Código de Conducta de Naciones Unidas enfrentó una dura resistencia de parte de gobiernos poderosos del norte, donde muchas ETNs tenían sus sedes”.

18 Para una visión contemporánea a esos desarrollos que hacía una comparación de los mismos, véase Seidl-Hohenveldern, I., "International Economic Law: General Course on Punlic International Law", Collected Courses of the Hague Academy of International Law, vol. 198, Leiden, Martinus Nijhoff, 1986, pp. 41 y 42.

19 OCDE, Declaración sobre inversión internacional y empresas multinacionales (21 de junio de 1976); sobre los orígenes de las Directrices de la OCDE, véase Muchlinski, P. T., op. cit., pp. 658 y 659 . 
las Exigencias Contradictorias, ${ }^{20}$ y los Incentivos y Desincentivos para la Inversión Internacional), en los cuales los gobiernos determinan tomar en consideración las medidas y propuestas acordadas para implementarlas en el ámbito de su competencia y jurisdicción.

En relación con el Trato Nacional, los gobiernos de los Estados parte de la OCDE acordaron asegurar a las empresas de origen extranjero que operen en su territorio la recepción de un trato no discriminatorio en relación con el recibido por las empresas nacionales en situaciones similares ${ }^{21} \mathrm{de}$ la misma forma, los Estados acordaron cooperar para evitar o minimizar la imposición de exigencias contradictorias a las empresas multinacionales, ${ }^{22}$

20 Este elemento, sin embargo, no se contemplaba explícitamente en la versión original de la Declaración sobre inversión internacional y empresas multinacionales de 1976. Fue adoptado en la revisión hecha en 1991 a la Declaración.

21 Para tal efecto, el instrumento establecido en torno al Trato Nacional contiene dos elementos: una declaración de principios — contenida en la Declaración sobre Inversión Internacional y Empresas Multinacionales - y una Decisión del Consejo de la OCDE sobre el procedimiento que data de 1991, por el que los Estados adherentes deben comunicar sus excepciones al Trato Nacional y que establece un mecanismo de seguimiento para tratar tales excepciones. El instrumento de Trato Nacional no es vinculante para los países adherentes, aunque existe un acuerdo unánime desde 1988 entre todos los países adherentes de no presentar nuevas excepciones al Trato Nacional. OCDE, The OECD Declaration and Decisions on International Investment and Multinational Enterprises: Basic Texts, 2012, pp. 29-32. Para una mayor profundización sobre el Trato Nacional desde una perspectiva académica, véanse Muchlinski, P. T., op. cit., pp. 621-628; Reinisch, A., Recent Developments in International Investment Law, París, Pedone, 2009, pp. 23-27, y Shan, W. , “Towards a Balanced Liberal Investment Regime: General Report on the Protection of Foreign Investment", ICSID Review-Foreign Investment Law Journal, vol. 25:2, 2010, p. 438: "National treatment (NT) is the other main standard that underpins the principle of non-discrimination under investment treaties. The purpose of this clause is to oblige a host state to make no negative differentiation between foreign and national investors".

22 Originalmente, se adoptaron algunas consideraciones generales y estrategias prácticas. Dentro de las consideraciones generales, los Estados acordaron que al contemplar la realización de ciertas acciones — adopción de nueva legislación u otro ejercicio jurisdiccional — que puedan imponer requisitos contradictorios a la ley o políticas de un país miembro, deberán tener en consideración los principios aplicables del derecho internacional, tener moderación y respetar los intereses de los demás países, tomar en cuenta la soberanía e intereses legítimos de los otros países miembros, y dar debida consideración a la importancia del cumplimiento de las obligaciones contractuales y al posible impacto adverso de medidas con efecto retroactivo; asimismo, acordaron promover la cooperación y consulta colectiva para la solución de problemáticas. Respecto de las estrategias prácticas, acordaron hacer énfasis en la cooperación bilateral, sin descartar las prácticas multilaterales, y dar debida consideración a los intere- 
y reconocieron la necesidad de dar debida consideración al interés de los países adherentes a la Declaración que hayan sido afectados por legislación o prácticas en el ámbito de la inversión internacional, así como de que las medidas adoptadas a nivel doméstico sean lo más transparentes posible. ${ }^{23}$

A pesar de la trascendencia de los tres instrumentos anteriormente descritos ${ }^{24}$ el elemento más importante de la Declaración sobre Inversión Internacional y Empresas Transnacionales son sin duda alguna las Directrices para las Empresas Multinacionales. La impresión general que existió durante esa época en torno a este instrumento es que fue la respuesta directa de los países industrializados al proyecto de desarrollo de normas vinculantes para empresas transnacionales que se llevaba en el seno de la Comisión sobre Empresas Transnacionales de la ONU. ${ }^{25}$ El objetivo

ses de otros Estados miembros cuando las medidas propias puedan afectar sus intereses. Sin embargo, a través de la Decisión del Consejo sobre exigencias contradictorias de 1991, se determinó que las consultas derivadas de la posible existencia de exigencias contradictorias se llevaran ante el Comité sobre Inversión Internacional y Empresas Multinacionales, que actúa como foro para la consideración de tales cuestiones, y donde las partes cooperarán de buena fe. Igualmente, se determinó invitar al Comité Asesor para Empresas e Industria (BIAC-Business and Industry Advisory Committee) y al Comité Asesor Sindical (TUAC-Trade Union Advisory Committee) a emitir sus opiniones respecto a asuntos relativos a exigencias contradictorias. OCDE, The OECD Declaration and Decisions on International Investment and Multinational Enterprises: Basic Texts, 2012, p. 33.

23 El instrumento sobre Incentivos y Desincentivos para la Inversión Internacional enfatiza la necesidad de fortalecer la cooperación internacional en el área de la inversión extranjera directa, de dar debida importancia a las medidas que incentiven o desincentivan la inversión, y que tales medidas sean lo más transparentes posibles. La Segunda Decisión del Consejo de la OCDE sobre este tema, de 1984, establece que cualquier consulta que deba realizarse se presentará ante el Comité sobre Inversión Internacional y Empresas Multinacionales cuando un Estado miembro considere que sus intereses puedan ser afectados adversamente, con el propósito de que se examine la posibilidad de reducir al máximo dichos efectos. Asimismo, los Estados parte que participen en los procedimientos de consulta deberán presentar toda la información permitida respecto a las medidas adoptadas, estando el Comité en posibilidad de invitar al BIAC y TUAC a emitir sus opiniones. Ibidem, p. 35.

24 Kauzlarich refería en 1981 que los instrumentos contenidos en la Declaración (las Directrices, el Trato Nacional y los Incentivos a la Inversión) fueron el primer proyecto exitoso para lograr acuerdos multilaterales en esta área de las relaciones económicas internacionales, mismos que tenían como objetivo el establecimiento de expectativas de comportamiento para las empresas y los gobiernos sin un elemento legal. Véase Kauzlarich, R. D., "The Review of the 1976 OECD Declaration on International Investment and Multinational Enterprises”, The American University Law Review, vol. 30, 1981, p. 1010.

25 Feeney, P., loc. cit., p. 178: "Los países ricos, temiendo el surgimiento de una inicia- 
de las Directrices fue establecer estándares aceptados de buenas prácticas para todas las empresas multinacionales operando en países miembros de la $\mathrm{OCDE}^{26}$ - y posteriormente fuera de ellos $-{ }^{27}$ con la finalidad de desarrollar un parámetro internacional común en relación con la inversión extranjera, particularmente entre aquéllos países que exportaban capital. En sí, como principios voluntarios que los gobiernos recomiendan a sus empresas, ${ }^{28}$ constituyen estándares para generar una conducta empresarial responsable, en una expresión práctica del concepto de la responsabilidad social empresarial, al no ser legalmente exigibles. ${ }^{29}$

Al realizar una comparación entre las versiones iniciales del Proyecto de Código de Conducta de la ONU para Empresas Transnacionales y de las Directrices de la OCDE para Empresas Multinacionales, resalta que las Directrices de la OCDE incluyeron en sus disposiciones la mayoría de los elementos que el proyecto de la ONU contemplaba en su sección sobre actividades empresariales en los ámbitos económico, financiero y social. Así, las Directrices de la OCDE contenían disposiciones relativas a la competencia,

tiva global de la ONU para regular a las empresas, se dirigieron a la Organización para la Cooperación y el Desarrollo Económico (OCDE) para una solución... La OCDE quería, en primer lugar y ante todo, proteger a los inversionistas internacionales de la discriminación y expropiación por parte de los gobiernos de los países de acogida”. Véase también Newcomb, A. y Paradell, L., op. cit., p. 33, quienes manifiestan que la Declaración de la OCDE de 1976 fue una respuesta de los Estados miembros de esa organización a la Declaración sobre un Nuevo Orden Económico Internacional y al proyecto de código de conducta para empresas transnacionales.

26 Keller, H., loc. cit., pp. 230 y 231.

27 La Declaración sobre Inversión Internacional y Empresas Transnacionales de 1976 establecía originalmente lo siguiente: "that they jointly recommend to multinational enterprises operating in their territories the observance of the Guidelines as set forth in the Annex here to having regard to the considerations and understandings which introduce the Guidelines and are an integral part of them"; OCDE, Declaración sobre inversión internacional y empresas multinacionales (21 de junio de 1976), §I (énfasis añadido); no fue sino hasta la actualización del año 2000 cuando se incluyó una referencia expresa a su aplicabilidad a las empresas que tuvieran su origen en un Estado Miembro de la OCDE, independientemente de su lugar de operaciones: "That they jointly recommend to multinational enterprises operating in or from their territories the observance of the Guidelines...”, OCDE, Declaración sobre inversión internacional y empresas multinacionales (27 de junio de 2000), §I (énfasis añadido)

28 Kauzlarich estima que el rol de las Directrices es alentar a las empresas transnacionales a realizar una contribución positiva y a minimizar y resolver las dificultades que puedan aparecer en torno a sus operaciones. Kauzlarich, R. D., loc. cit., p. 1027.

29 Sobre este punto se ahondará mayormente en la siguiente sección. 
el financiamiento, los impuestos, el empleo y las relaciones industriales, y la ciencia y tecnología, que se reproducían de manera similar en el código de la ONU, con la excepción de lo relativo a la divulgación de información.

Sin embargo, no contemplaban las medidas generales sobre las que habían insistido mayormente los países en vías de desarrollo en el seno de la ONU, respecto a áreas como la soberanía nacional o la adhesión de las empresas a los objetivos económicos o socioculturales del país receptor de la inversión. Asimismo, las Directrices de la OCDE para Empresas Multinacionales no contenían referencias explícitas sobre el trato que habrían de recibir las empresas, mientras que el proyecto de Código de Conducta de la ONU sí establecía medidas referentes a la nacionalización y compensación, a la competencia jurisdiccional o a la solución de controversias. Desde luego, el hecho de que el Código de Conducta de la ONU haya sido concebido como un instrumento obligatorio para las empresas, mientras que las Directrices de la OCDE están dotadas de un carácter voluntario ${ }^{30}-\mathrm{y}$ constituyen solo recomendaciones prácticas de los gobiernos a las empresas respecto a estándares de conducta empresarial aceptados globalmente en el marco del derecho internacional de las inversiones--, se extiende hacia su contenido y se ve reflejado en la estructura de los instrumentos donde se concretaron las posturas de los distintos países intervinientes. ${ }^{31}$

30 Sobre esto, $c f r$. Rubin, S. J., "Transnational Corporations and International Codes of Conduct. A Study of the Relationship Between International Legal Cooperation and Economic Development”, American University International Law Review, vol. 10:4, 1995, p. 1285 : "Even codes explicitly declared to be "voluntary", such as the OECD Guidelines, may establish norms of conduct that would probably be observed - perhaps as much as if they were formally "mandatory". On the other hand, codes explicitly worded to create non-binding obligations may be considered interpretive of other explicitly binding agreements".

31 En cierta forma, se puede considerar que resultó más sencillo lograr un consenso entre países con posiciones y condiciones similares en el seno de la OCDE, que en el vasto horizonte que representa la Organización de las Naciones Unidas. En ese sentido se expresa Kothari: “En premier lieu, le fait que l'Organisation soit constituée de 34 pays membres liés par des perspectives communes permet d'atteindre un consensus relativement rapide autour d'un nouveau standard, surtout si l'; on compare l' OCDE à des organisations à caractère universel telles que les Nations Unies, qui doivent opérer un consensus entre 193 pays aux vues parfois totalement divergentes. De ce fait, l'OCDE a souvent été la première organisation intergouvernementale à trouver un accord sur un nouvel instrument répondant à un défi émergent". Kothari, G., "L'élaboration des principes et standards à l'intention des entreprises: L'approche innovante de l'OCDE”, en S. F. D. I., Le pouvoir normatif de l'OCDE, París, Pedone, 2013, p. 107. 
Las Directrices de la OCDE para Empresas Multinacionales han sido revisadas en diferentes ocasiones (en 1979, 1984, 1991, 2000 y 2011), en las que se han actualizado progresivamente conforme al desarrollo de la economía internacional, añadiéndose en tales revisiones diferentes elementos a su contenido sustantivo. De las últimas revisiones, uno de los principales desarrollos fue la creación de un mecanismo para dar seguimiento a las inconformidades que surgieran respecto a la implementación de las Directrices, que tuvo lugar en el año 2000. Otro desarrollo importante que también constituyó un paradigma fue la homogeneización de las Directrices con otros desarrollos normativos a nivel internacional relativos a la conducta empresarial, derivados particularmente de la Organización de las Naciones Unidas. A ambos casos nos referiremos en las siguientes secciones.

Otro elemento a considerar es que desde su versión original, las Directrices han contenido algunas referencias implícitas a los derechos humanos, como el señalar en su apartado sobre Políticas Generales la importancia de tener en consideración el progreso económico y social del país donde operen, ${ }^{32}$ evitar la discriminación laboral con base en la nacionalidad, ${ }^{33} \mathrm{O}$ bien respetar los derechos laborales de naturaleza individual y colectiva de sus empleados. ${ }^{34}$ Como se verá más adelante, esta disposición en la versión original de las Directrices ha evolucionado a través de las revisiones y modificaciones hechas al anexo de la Declaración, logrando ser cada vez más inclusiva de los derechos humanos contemplados en el ámbito internacional y reconocidos por la comunidad internacional.

Finalmente, una característica importante de la Declaración de la OCDE sobre la Inversión Internacional y las Empresas Multinacionales es que desde su concepción ha sido considerada como una propuesta de los países "ricos" para perpetuar el dominio económico sobre los países en vías de desarrollo. Sin embargo, teniendo en cuenta que en la actualidad numerosas empresas transnacionales y flujos de capital provienen de países del "Sur Global”, y que los países industrializados han cedido una cantidad importante de su poderío económico a las empresas mismas y a otros agentes del

32 OCDE, Declaración sobre inversión internacional y empresas multinacionales (21 de junio de 1976), Anexo, p. 13 (en lo sucesivo nos referiremos al Anexo como Directrices para Empresas Multinacionales)

33 Ibidem, p. 14.

34 Ibidem, pp. 16 y 17. 
ámbito económico mundial, cabe interrogarse sobre la validez y solidez de ese argumento, y sobre su pertinencia en un mundo en que las fronteras y jurisdicciones se vuelven cada vez más opacas para ceder su lugar a una economía transnacional dinámica y vertiginosa. ${ }^{35}$

\section{LA ACTUALIZACIÓN DE 2011 DE LAS DIRECTRICES, Y LA INCLUSIÓN EXPLÍCITA DE LOS DERECHOS HUMANOS}

La presente sección tiene como objetivo analizar el estado actual de las Directrices de la OCDE para Empresas Multinacionales, que fueron revisadas por última vez en el año 2011, así como observar el paulatino desarrollo que han tenido los derechos humanos en este instrumento en las últimas revisiones. Para ello, procederemos primeramente a analizar los cambios sustantivos en este instrumento en sus últimas dos revisiones, de 2000 y 2011, lo cual ha permitido que los derechos humanos tengan un papel cada vez más relevante en la estructura de las Directrices.

Desde su primera versión en 1976, las Directrices de la OCDE para Empresas Multinacionales han contenido referencias a los derechos labores de naturaleza individual y colectiva, ${ }^{36}$ ampliamente considerados como derechos incluidos en el catálogo de prerrogativas económicas, sociales y culturales. Sin embargo, otras secciones de las Directrices fueron progresivamente haciendo énfasis en situaciones relativas a los derechos humanos sobre las que las empresas a quienes éstas eran aplicables debían tomar en consideración. Tal es el caso, por ejemplo, de la referencia a tomar medidas para evitar daños a la salud de las personas, así como a la realización de estudios de impacto ambiental y a la toma de medidas para garantizar una

35 Álvarez, J. E., The Public International Law Regime Governing International Investment, Leiden, Brill, 2011, pp. 243 y 244: "That the investment regime is having an impact on the general law should not be seen, as it sometimes is, as a triumph of the Global North over the South or of investors over the regulatory power of States. The contemporary investment regime, as is addressed in prior chapters, is now too universal in scope and includes too many prominent first movers from the «Global South» to be credibly portrayed in such terms. It has, to this extent, outgrown its origins".

36 Feeney, P., loc. cit., p. 178: "Si bien estas directrices incorporaron algunos derechos laborales, no hacían referencia explícita a otros derechos humanos". 
debida diligencia en este ámbito, contenidas en la sección sobre Protección Ambiental que se incluyó en las Directrices en 1991. ${ }^{37}$

No obstante, fue en la revisión del año 2000 cuando finalmente se adoptaron referencias explícitas ${ }^{38}$ a los derechos humanos en este instrumento de la OCDE. ${ }^{39}$ Esta revisión fue de carácter integral, puesto que se rediseñó la estructura y áreas a las que hacían referencia las Directrices, y de forma general su contenido. Así, en su sección sobre Políticas Generales, se estableció que las empresas debían respetar los derechos humanos de aquellas personas afectadas por sus actividades, de una forma consistente y respetuosa de las obligaciones y compromisos internacionales del país receptor de la inversión. ${ }^{40}$ De la misma manera, se estableció que las empresas deberían abstenerse de buscar o aceptar exenciones relativas al medio ambiente, la salud, la seguridad, las relaciones laborales, la fiscalización, o los incentivos fiscales, entre otras, que no estuvieran previamente contempladas en los marcos legislativos o regulatorios correspondientes; ${ }^{41}$ lo anterior tenía como objetivo que las empresas evitaran negociar la adopción de cláusulas de estabilización ${ }^{42}$ que pudieran limitar la capacidad regulatoria del gobierno, en detrimento inter alia de los derechos humanos de los ciudadanos del país receptor de la inversión.

Otros aspectos que recientemente han cobrado una mayor relevancia en el ámbito de los derechos humanos son las cadenas de suministro en

37 OCDE, Directrices para Empresas Multinacionales (junio de 1991).

38 Jägers, N., Corporate Human Rights Obligations: in Search of Accountability, Antwerp, Intersentia, 2002, p. 103: "Before the revision of June 2000, the Guidelines did not explicitly provide that corporations should observe human rights".

39 Para una referencia específica sobre la revisión del año 2000 de las Directrices de la OCDE para Empresas Multinacionales, véanse Tully, S., "The 2000 Review of the OECD Guidelines for Multinational Enterprises”, International and Comparative Law Quarterly, vol. 50(2), 2001, y Clapham, A., Human Rights Obligations of Non-State Actors, Oxford, Oxford University Press, 2006, pp. 204 y 205. Para una reseña informativa sobre las Directrices previo a la revisión del año 2000, véase Karl, J., “The OECD Guidelines for Multinational Enterprises”, en Addo, M. K. (ed.), Human Rights Standards and the Responsibility of Transnational Corporations, La Haya, Kluwer Law International, 1999.

40 OCDE, Directrices para Empresas Multinacionales (27 de junio de 2000), §II.2.

41 Ibidem, §II.5.

42 Sobre las cláusulas de estabilización, véase Morgera, E., Corporate Accountability in International Environmental Law, Oxford, Oxford University Press, 2009, p. 27. 
el contexto de las empresas transnacionales, ${ }^{43}$ así como el requerimiento de presentar informes extra-financieros respecto a la operación y medidas tomadas por las empresas, particularmente en torno a políticas sociales, éticas o ambientales. ${ }^{44}$ Ambas se encontraban contempladas en la versión del año 2000 de las Directrices de la OCDE para Empresas Multinacionales. Al respecto, el Comentario a las Directrices subraya la importancia que tiene para las empresas el respetar los derechos humanos, no solo en el círculo de sus relaciones laborales (lo cual es legalmente exigible), sino también respecto a terceros que se vean afectados por las actividades empresariales. ${ }^{45}$

La progresiva aparición de referencias a los derechos humanos en el marco de las Directrices para Empresas Multinacionales de este organismo se vio igualmente acompañada por la reaparición del debate en el seno de las Naciones Unidas. Si bien previo a la revisión de 2000 esta situación fue relativamente tenue, ${ }^{46}$ cobró mayor relevancia a partir de 2005, en que John Ruggie fue nombrado representante especial del secretario general de las Naciones Unidas para la cuestión de los derechos humanos y las empresas transnacionales y otras empresas comerciales. Desde su primer

43 OCDE, Directrices para Empresas Multinacionales (27 de junio de 2000), §II.10: "Encourage, where practicable, business partners, including suppliers and sub-contractors, to apply principles of corporate conduct compatible with the Guidelines".

44 Ibidem, §III.5a. Sobre esto se han adoptado regulaciones en los Estados Unidos y en la Unión Europea; véanse Dodd-FrankWall Street Reform and Consumer Protection Act, \$1502, sobre la revelación del uso de minerales provenientes de zonas conflictivas en o alrededor de la República Democrática del Congo; y Directive 2014/... / EU regarding disclosure of non-financial and diversity information by certain large undertakings and groups, COM/2013/0207 final (15 de abril de 2014), conforme a la cual las grandes empresas europeas deberán incluir en sus reportes información relativa a los impactos de sus actividades en los derechos humanos. El Comentario de las Directrices hace referencia a la revelación de información extra-financiera, reconociendo que tales estándares se encontraban aún en fase de desarrollo en esa época; sin embargo, reconoce también que constituyen un método para demostrar el compromiso empresarial con prácticas socialmente aceptables. OCDE, Comentario a las Directrices de la OCDE para Empresas Multinacionales, 2000, §14.

45 OCDE, Comentario a las Directrices de la OCDE para Empresas Multinacionales, $2000, \S 4$.

46 La principal llamada a que las empresas respetaran los derechos humanos previo a la revisión de la Directrices en el año 2000 fue el lanzamiento del Pacto Mundial de las Naciones Unidas (Global Compact), que en 1999 incluyó un breve capítulo sobre derechos humanos dentro de los —entonces - nueve principios que ostentaba. 
informe a la entonces Comisión de Derechos Humanos, ${ }^{47}$ Ruggie señaló el potencial de las Directrices de la OCDE para Empresas Multinacionales, y en particular de su mecanismo de implementación, los Puntos de Contacto Nacional, para resolver cuestiones relativas al impacto de las actividades empresariales en los derechos humanos; sin embargo, criticó la disparidad entre los procedimientos de los diferentes países, alimentados sin duda por la diferente percepción y conocimiento sobre el alcance de las Directrices.

La última revisión del instrumento de la OCDE tuvo lugar en el año 2011, momento en que John Ruggie emitió los Principios Rectores de Naciones Unidas sobre Empresas y Derechos Humanos. La adopción de estos Principios Rectores implicó un cambio de paradigma dentro del tema de las empresas y los derechos humanos, puesto que se convirtió en el punto de convergencia y de arranque de una nueva discusión, con una perspectiva de menor confrontación y de mayor colaboración entre las diferentes partes involucradas. ${ }^{48}$ Es importante señalar que los Principios Rectores de Naciones Unidas sobre Empresas y Derechos Humanos fueron la base para la reforma de las Directrices de la OCDE para Empre-

47 Informe provisional del Representante Especial del Secretario General sobre la cuestión de los derechos humanos y las empresas transnacionales y otras empresas comerciales, E/CN.4/2006/97 (22 de febrero de 2006), §41: “Una característica distintiva de las líneas directrices de la OCDE para empresas multinacionales es el sistema de los Puntos Nacionales de Contacto (PNC). Se trata de oficinas de la administración pública de los países participantes que, entre otras funciones, atenderán "casos concretos" (denuncias, en lenguaje común) de incumplimiento de las directrices por una empresa. Puede presentarlas cualquier persona u organización y la mayoría procede de organizaciones sindicales. Este mecanismo tiene un enorme potencial para contribuir a resolver los problemas de las empresas en los derechos humanos porque no sólo cubre aspectos en el plano nacional sino también en los países receptores. Pero los resultados de los PNC son muy desiguales, especialmente en cuanto a los derechos humanos. Su modesta contribución actual podría mejorar con la uniformización de las prácticas y una mayor rendición pública de cuentas" (énfasis añadido).

48 Así lo reconoce explícitamente el antiguo Representante Especial para la cuestión de empresas y derechos humanos. Véase Ruggie, J. G., Just Business: Multinational Corporations and Human Rights, Nueva York, W.W. Norton, 2013, p. 159: "Unanimous endorsement by the Human Rights Council ensured that the Guiding Principles became the authoritative UN standard for business and human rights. But by itself this would not necessarily mean that other relevant international standard-setting bodies would automatically defer to the UN and align their own standards with the GPs. Different institutions have different missions, and these often reflect the sectoral or regional interests and concerns that are represented in them. Therefore, achieving convergence around the GPs required an active engagement effort”. 
sas Multinacionales, ${ }^{49}$ por lo que es importante hacer referencia - por lo menos de forma breve- $-{ }^{50}$ al contenido e innovaciones del proyecto de la ONU.

Los Principios Rectores de Naciones Unidas sobre Empresas y Derechos Humanos se basan en tres pilares: el deber del Estado de proteger contra violaciones de derechos humanos, incluyendo aquéllos cometidos por empresas; la responsabilidad empresarial de respetar los derechos humanos reconocidos a nivel internacional, a través de la adopción de medidas como debida diligencia en materia de derechos humanos y evaluaciones de impacto a través de sus operaciones, y finalmente, en la necesidad de que exista un mayor acceso a recursos jurídicos y no jurídicos que permitan remediar adecuadamente y de forma integral los daños sufridos por las víctimas de tales violaciones. ${ }^{51}$ La principal aportación de este marco conceptual fue la identificación de la responsabilidad de las empresas en

49 Ibidem, p. 161: "Facing the possibility that the UN and the OECD might produce different and possibly conflicting business and human rights standards, business associations began to call for convergence... The Trade Union Advisory Committee to the OECD was equally supportive of the idea, as was OECD Watch, its civil society counterpart." Sin embargo, Dubin considera que una fabricación "masiva" de estándares para diferentes organismos tiene serios límites: cfr. Dubin, L., "L'élaboration des principes à l'intention des entreprises multinationales par l'OCDE ou comment globaliser la régulation du comportement d'un acteur global?", en S.F.D.I., Le pouvoir normatif de l'OCDE, París, Pedone, 2013, p. 124.

50 Una cantidad importante de literatura jurídica — a favor y en contra - se ha desarrollado en torno a estos Principios Rectores y al Mandato del Representante Especial para la cuestión de los derechos humanos y las empresas transnacionales, primordialmente en lengua inglesa. Para una aproximación primariamente favorable, véase Mares, R. (ed.), The UN Guiding Principles on Business and Human Rights: Foundations and Implementation, Leiden, Martinus Nijhoff, 2012; Addo, M. K., "The Reality of the United Nations Guiding Principles on Business and Human Rights", Human Rights Law Review, vol. 14 (1), 2014; cfr. Deva, S. y Bilchitz, D. (eds.), Human Rights Obligations of Business: Beyond the Corporate Responsibility to Respect?, Cambridge, Cambridge University Press, 2013; en español, véanse Cantú Rivera, H. F., "Empresas y derechos humanos: ¿hacia una regulación jurídica efectiva, o el mantenimiento del status quo?", Anuario Mexicano de Derecho Internacional, vol. XIII, 2013; Cantú Rivera, H. F., "Evaluando los Principios Rectores sobre Empresas y Derechos Humanos a dos años de su adopción', Revista Internacional de Derechos Humanos, núm. 3, CLADH-Universidad de Zaragoza, 2013; Zamora, F. J., García Cívico, J. y Sales Pallarés, L. (eds.), La responsabilidad de las multinacionales por violaciones de derechos humanos, Alcalá de Henares, Universidad de AlcaláDefensor del Pueblo, 2013.

51 Informe del Representante Especial del Secretario General para la cuestión de los derechos humanos y las empresas transnacionales y otras empresas, Principios Rectores sobre las 
el ámbito de los derechos humanos, misma que se vería acompañada por medidas prácticas con las que están usualmente familiarizadas, para establecer procedimientos al interior de la empresa que les permitan prevenir - y en caso necesario remediar - los impactos negativos en los derechos humanos que sus actividades puedan generar.

La actualización de las Directrices de la OCDE para Empresas Multinacionales tuvo como objetivo alinear dicho instrumento con los estándares y mejores prácticas internacionales, a fin de contribuir a un desarrollo normativo equitativo a nivel internacional en el ámbito de la responsabilidad de las empresas en materia de derechos humanos. De esta manera, la revisión del año 2011 tuvo como novedad principal la inclusión de un capítulo sobre derechos humanos que, tomando como punto de referencia los Principios Rectores de la ONU sobre empresas y derechos humanos, establecía la responsabilidad de las empresas de respetar los derechos humanos y de adoptar procedimientos para asegurar y demostrar ("know \& show" $)^{52}$ su puesta en práctica. Este nuevo capítulo establece que las empresas deben velar por el respeto de tres marcos regulatorios: de los derechos humanos internacionalmente reconocidos (es decir, la Carta Internacional de Derechos Humanos y la Declaración de la OIT relativa a los principios y derechos fundamentales en el trabajo de 1998); de los tratados de derechos humanos suscritos por los Estados donde éstas realizan sus operaciones, y finalmente, de las leyes y regulaciones nacionales aplicables en los países donde la empresa tenga sus actividades. ${ }^{53}$

empresas y los derechos humanos: puesta en práctica del marco de las Naciones Unidas para "proteger, respetar y remediar”, A/HRC/17/31 (21 de marzo de 2011).

52 Véase Kauzlarich, R. D., loc. cit., p. 1026, quien hacía referencia a esto en 1981: “The OECD governments have recommended the Guidelines to enterprises that are now free to react to them. Enterprises probably will find the Guidelines consistent with their corporate activities and will be able to express public support for them... there will be no contract to sign or law to obey, simply the commitment of the enterprise to follow its words with deeds" (énfasis añadido).

53 OCDE, Directrices para Empresas Multinacionales (25 de mayo de 2011). Desde luego, los dos últimos marcos (las obligaciones internacionales del Estado receptor de la inversión, y la legislación y reglamentos nacionales en vigor) pueden generar conflictos respecto a los estándares aplicables, los cuales no necesariamente serán idénticos en todos los puntos geográficos de operación de la empresa. Véase McBeth, A. y Nolan, J., "The International Protection of Human Rights and Fundamental Freedoms”, en Tully, S. (ed.), International Corporate Legal Responsibility, Alphen aan den Rijn, Kluwer Law International, 2012, p. 189. Para una intere- 
El capítulo sobre derechos humanos establece seis puntos relativos a la responsabilidad de las empresas, complementados por diversos comentarios respecto al alcance y significado de cada uno de los postulados. En primer término, establece que respetar los derechos humanos equivale a no vulnerar tales prerrogativas, así como a hacer frente a los impactos negativos que sus actividades generen. ${ }^{54}$ Según el Comentario de las Directrices, la "responsabilidad" de hacer frente a los impactos negativos implica un procedimiento de cinco niveles, que consiste en tomar medidas para detectar dónde se encuentran los factores de riesgo; prevenir los posibles impactos negativos en la medida de lo posible; atenuar los impactos potenciales; remediar los daños cuando éstos ocurran, y rendir cuentas sobre las medidas adoptadas para hacer frente a su responsabilidad de respetar. ${ }^{55}$

Las empresas, conforme al Capítulo IV de las Directrices, tienen igualmente la responsabilidad de evitar impactos negativos a los derechos humanos o de contribuir a ellos en el marco de sus actividades, así como la responsabilidad de resolverlos cuando éstos existan. ${ }^{56}$ Por actividades, conforme al Comentario, se hace referencia a todas aquellas acciones $\mathrm{u}$ omisiones que sean resultado de la actividad empresarial. ${ }^{57}$ Un tercer postulado indica que si bien la responsabilidad principal de la empresa existe respecto a sus propias actividades, ésta debe también prevenir y atenuar los impactos negativos en los derechos humanos que se relacionen indirectamente a la empresa, por ejemplo a través de una relación comercial,

sante propuesta sobre principios jurídicos contradictorios y cómo resolver la disyuntiva sobre cuál principio aplicar, véase Deva, S., Regulating Corporate Human Rights Violations: Humanizing Business, Londres, Routledge, 2012, p. 160.

54 OCDE, Directrices para Empresas Multinacionales (25 de mayo de 2011), §IV.1. Este punto en particular contiene, sin embargo, un trasfondo jurídico, al referirse a enfrentar los impactos ocasionados; en sí, es una alusión — tal vez no deseada - a la responsabilidad jurídica, al menos en términos de derecho internacional. Sobre la responsabilidad en el derecho internacional, particularmente sobre sus acepciones como obligación y como deber, véase Chaumette, A.L., 'La responsabilité de protéger, interrogations sémantiques', en Chaumette, A. L. y Thouvenin, J. M., La responsabilité de protéger, dix ans après, París, Pedone, 2013, pp. 14 y 15.

55 OCDE, Comentario a las Directrices de la OCDE para Empresas Multinacionales, $2011, \S 41$.

56 OCDE, Directrices para Empresas Multinacionales (25 de mayo de 2011), §IV.2.

57 OCDE, Comentario a las Directrices de la OCDE para Empresas Multinacionales, $2011, \S 42$. 
aun cuando la empresa no contribuya a dichos impactos. ${ }^{58}$ Este punto, de alta complejidad al momento de trasladar el texto a la práctica, implica que la empresa debe tratar de alentar a la empresa directamente responsable a impedir o atenuar el impacto, a través de su poder de influencia, ${ }^{59} \mathrm{y}$ actuando sola o en conjunto con otras entidades que puedan influir sobre las decisiones de la empresa responsable. ${ }^{60}$ Este postulado contiene amplias referencias a una actuación ética de la empresa multinacional y sin embargo, su realización práctica aparenta ser difícil, salvo que se establezca de forma contractual con sus socios comerciales y las correspondientes cadenas de suministro, de manera que su aplicación y respeto se vuelva exigible desde un punto de vista jurídico. ${ }^{61}$

El cuarto párrafo del capítulo sobre derechos humanos hace referencia, por su parte, al establecimiento de una política empresarial de respeto de los derechos humanos, ${ }^{62}$ que debe adoptarse al más alto nivel jerárquico y

58 OCDE, Directrices para Empresas Multinacionales (25 de mayo de 2011), §IV.3.

59 Nieuwenkamp, R., “Cut and run, or stay and help?", Ethical Corporation, marzo de 2014: "If a breach of the OECD Guidelines occurs, companies should first use their influence to try to improve the situation in their supply chain. If they lack the leverage to do so, they should try to increase their influence, for example through co-operating with other companies, trade unions or NGOs. Improvement is the best solution. Disengagement is the last resort" (enfasis añadido).

60 OCDE, Comentario a las Directrices de la OCDE para Empresas Multinacionales, 2011, §43. Algunos juristas explican la motivación de esta disposición: "The approach to due diligence that extends its reach beyond the legal boundary of the individual company to include its business relationships also recognizes that business relationships cross national boundaries. Part of the rationale for extending the reach of due diligence provisions to include business relationships is to respond to the problems posed by the reality of the integration of global commercial activity, which makes regulatory oversight by any one regulator both difficult and complex". De Schutter, O. et al., Human Rights Due Diligence: The Role of States, ICAR/ECCJ, 2012, p. 51. No obstante el énfasis y celebración en torno a la inclusión de esta responsabilidad sobre la cadena de suministro, debe señalarse que ya en la revisión del año 2000 se hacía referencia a ello, en el capítulo sobre Políticas Generales; véase Clapham, A., op. cit., p. 203: "The reach of the Guidelines, then, extends right down the chain to the smallest sub-contractors, with the emphasis on the multinational to encourage others with which it is in contact to respect the Guidelines".

61 Sobre este punto, véase Mares, R., "Responsibility to Respect: Why the Core Company Should Act When Affiliates Infringe Human Rights”, en Mares, R. (ed.), The UN Guiding Principles on Business and Human Rights: Foundations and Implementation, Leiden, Martinus Nijhoff, 2012 .

62 OCDE, Directrices para Empresas Multinacionales (25 de mayo de 2011), §IV. 4. 
difundirse e implementarse a través de toda la estructura corporativa de la empresa, además de ser comunicada a los distintos socios comerciales. ${ }^{63}$

El quinto párrafo, por su parte, contiene la principal adición sustantiva a las Directrices de la OCDE para Empresas Multinacionales, al establecer que las empresas deberán: "Ejercer la debida diligencia en materia de derechos humanos en función de su tamaño, de la naturaleza y el contexto de sus actividades y de la gravedad de los riesgos de impactos negativos sobre dichos derechos". ${ }^{64}$ En el Comentario a las Directrices, se establece que este procedimiento debe contar con cinco fases progresivas: "Este proceso implica evaluar los impactos reales o potenciales sobre los derechos humanos, integrar los resultados de dicha evaluación y poner en práctica las acciones correspondientes, hacer un seguimiento de las respuestas y comunicar las medidas tomadas para hacer frente a los impactos" ${ }^{65}$

El tema reflejado en esta disposición, que ha sido comentado ampliamente por la doctrina a nivel internacional, ${ }^{66}$ adapta las recomendaciones hechas por John Ruggie respecto a los mecanismos y procedimientos de debida diligencia que las empresas deben poner en práctica para evitar o limitar sus impactos en la esfera de los derechos humanos. ${ }^{67}$ Sin embargo, para algunos otros juristas es necesario que tales procedimientos - al igual que lo hizo John Ruggie durante su mandato - incluyan la participación de actores externos, a fin de brindar mayor legitimidad y posibilidad de segui-

63 OCDE, Comentario a las Directrices de la OCDE para Empresas Multinacionales, $2011, \S 44$.

64 OCDE, Directrices para Empresas Multinacionales (25 de mayo de 2011), §IV.5.

65 OCDE, Comentario a las Directrices de la OCDE para Empresas Multinacionales, $2011, \S 45$.

66 Véanse por ejemplo, Martín-Ortega, O., "Human Rights Due Diligence for Corporations: From Voluntary Standards to Hard Law at Last?”, Netherlands Quarterly of Human Rights, vol. 31(4), 2013, pp. 49 y 50, 55-60; Lambooy, T., "Corporate Due Diligence as a Tool to Respect Human Rights”, Netherlands Quarterly of Human Rights, vol. 28 (3), 2010; Harrison, J., "Human Rights Measurement: Reflections on the Current Practice and Future Potential of Human Rights Impact Assessment”, Journal of Human Rights Practice, vol. 3 (2), 2011.

67 Respecto a la implementación de requerimientos de debida diligencia por los Estados en legislaciones nacionales, y en particular sobre estándares comunes que éstas deben incluir, véase De Schutter, O. et al., Human Rights Due Diligence:The Role of States, ICAR/ECCJ, 2012, pp. 55-57. 
miento a la implementación de las modificaciones operativas que deriven de los resultados de la debida diligencia al interior de la empresa. ${ }^{68}$

Finalmente, el cuarto capítulo se ve redondeado con una disposición relativa al establecimiento por parte de la empresa - o su cooperacióncon los mecanismos pertinentes para remediar los impactos negativos en los derechos humanos que haya causado o a los que haya contribuido. ${ }^{69} \mathrm{La}$ recomendación se centra, pues, en cooperar con los mecanismos judiciales o no judiciales establecidos por el Estado, o bien en participar a través de los mecanismos que existan al interior de la empresa. De igual manera, el Comentario establece que los mecanismos de reparación que llegasen a existir en el seno empresarial deben cumplir con ciertos criterios para considerarse adecuados, y no limitar o impedir la función de los sindicatos ni el acceso a mecanismos judiciales o no judiciales, incluyendo a los Puntos de Contacto Nacional. ${ }^{70}$

En cuanto a su parte sustantiva, las principales adiciones aportadas por el Capítulo sobre Derechos Humanos a las Directrices de la OCDE para Empresas Multinacionales son, en primer lugar, la inclusión de una responsabilidad de las empresas de contar con procedimientos de debida diligencia para identificar, prevenir y en su caso remediar los impactos negativos en los derechos humanos, y en segundo lugar, la responsabilidad de supervisar sus cadenas de suministro y sus círculos de negocios, a fin de alentar una conducta empresarial responsable durante todo el ciclo productivo. ${ }^{71}$

68 Véase en particular Harrison, J., "Establishing a meaningful human rights due diligence process for corporations: learning from experience of human rights impact assessment", Impact Assessment and Project Appraisal, vol. 31 (2), 2013, p. 108: “... there are certain core essential issues, beyond those set out by Ruggie, that must also be addressed if human rights due diligence is to be effective. Three requirements are set out that must become integral to the HRDD process: requirements of transparency; external participation and verification; and independent monitoring and review".

69 OCDE, Directrices para Empresas Multinacionales (25 de mayo de 2011), §IV.6.

70 OCDE, Comentario a las Directrices de la OCDE para Empresas Multinacionales, 2011, §46. Los criterios que los mecanismos empresariales de reparación deben cumplir, de conformidad con el Comentario, son: legitimidad, accesibilidad, previsibilidad, equidad, compatibilidad con las Directrices y transparencia, además de basarse en el diálogo y en la voluntad de alcanzar soluciones.

71 Černič, J. L., "The 2011 Update of the OECD Guidelines for Multinational Enterprises”, American Society of International Law Insights, vol. 16 (4), 2012, pp. 1 y 2; Ruggie, J. G., op. cit., p. 122: “The Guidelines' new human rights chapter, due diligence requirement, and 
Por otra parte, en lo que respecta a la implementación del instrumento de la OCDE, las modificaciones hechas a las Directrices sobre la actuación de los Puntos de Contacto Nacional fueron también de singular importancia, por lo que serán analizadas en la siguiente sección.

El objetivo principal de las Directrices de la OCDE para las Empresas Multinacionales, que continúa viéndose reflejado en los resultados de su última revisión, es la estandarización de normas a nivel internacional, con la finalidad de que los Estados y empresas de su nacionalidad que exporten capital y participen en el desarrollo económico internacional y en la inversión extranjera tengan un común denominador que rija sus actividades y comportamiento, ${ }^{72}$ así como de propiciar la existencia de garantías de seguridad jurídica generalizadas en el marco de la inversión internacional. ${ }^{73} \mathrm{De}$ esta manera, el hecho de que se adopte un estándar mínimo respecto a la conducta esperada de las empresas a nivel internacional tiende a combatir la existencia de prácticas que atentan contra los derechos humanos en la búsqueda de mayores ganancias, particularmente en países en vías de desarrollo con carencias estructurales y gubernamentales. ${ }^{74}$

Los Estados, por su parte, tienen una doble obligación: de implementar las Directrices ${ }^{75}$ — lo que les impone el deber de promover su adopción por

explicit extension to include supply chains, drawn from the GPs, expands the scope of this mechanism". Véase, sin embargo, la aclaración respecto a las cadenas de suministro en la referencia a Clapham, supra.

72 Kothari, G., loc. cit., p. 108. Para Kothari, lo anterior representa una garantía para una competencia equitativa que va más allá de los argumentos morales, puesto que para los Estados la justificación se encuentran en el ámbito económico, a través de la adopción de reglas comunes a nivel internacional.

73 Decaux, E., “Le projet de l'ONU sur la responsabilité des entreprises transnationales”, en Daugareilh, I. (ed.), Responsabilité sociale de l'entreprise transnationale et globalisation de l'économie, Bruselas, Bruylant, 2010, pp. 468 y 469.

74 Lo anterior es reconocido en el Prefacio de las propias Directrices. OCDE, Directrices para Empresas Multinacionales (25 de mayo de 2011), Prefacio: “6... En la actualidad, la competencia es intensa y las empresas multinacionales se enfrentan a una gran variedad de marcos legales, sociales y normativos. En este contexto, las empresas podrían verse tentadas a descuidas las normas y principios de conducta adecuados con el fin de obtener una ventaja competitiva indebida. Estas prácticas de unas pocas empresas podrían poner en duda la reputación de la mayoría de ellas y generar preocupación en los ciudadanos”.

75 Véase Tully, S., "The 2000 Review of the OECD Guidelines for Multinational Enterprises", International and Comparative Law Quarterly, vol. 50(2), 2001, p. 400: "The Guidelines are not enforced per se: States are responsible for promoting their implementation, principally 
parte de las empresas, ${ }^{76} \mathrm{y}$ de establecer las estructuras correspondientes a nivel interno- - y de proteger los derechos humanos de los impactos que en ellos pueda ocasionar la actividad empresarial. Aunado a esa obligación estatal, los Estados, a través de las Directrices de la OCDE para Empresas Multinacionales, han optado por promover prácticas internacionalmente reconocidas de conducta empresarial responsable, con la finalidad de que las empresas contribuyan al desarrollo sostenible y a través de ello, reflejen los valores y aspiraciones de los países miembros de la OCDE. ${ }^{77}$

Una de las principales críticas a las Directrices para Empresas Multinacionales es su carácter voluntario o no vinculante, situación que no es única en el ámbito de la responsabilidad de las empresas a nivel internacional. ${ }^{78}$ El carácter voluntario de esta iniciativa ha estado presente desde su concepción en 1976, se encuentra determinado de forma explícita en el texto de las Directrices, y ha sido ferozmente defendido por el representante empresarial ante la OCDE, el BIAC. ${ }^{79}$ En particular, se señala que esa concepción de las Directrices como una disposición voluntaria las convierte en opcionales, lo que reduce su eficacia y aplicación, y se convierte en una justificación para no tomar medidas destinadas a tener un comportamiento responsable. ${ }^{80}$

through NCPs, and in the event of a dispute, business, trade unions and other interested parties may question their application to the particular circumstances".

76 OCDE, Directrices para Empresas Multinacionales (25 de mayo de 2011), Prefacio.: "1... Las Directrices enuncian principios y normas voluntarias para una conducta empresarial responsable compatible con las legislaciones aplicables y las normas reconocidas internacionalmente. Sin embargo, los países que se adhieren a las Directrices contraen el compromiso vinculante de implementarlas de acuerdo con la Decisión del Consejo relativa a las Líneas Directrices de la OCDE para Empresas Multinacionales".

77 Keller, H., loc. cit., p. 231; Tully, S., "Introduction”, en Tully, S. (ed.), International Corporate Legal Responsibility, Alphen aan den Rijn, Kluwer Law International, 2012, p. 53.

78 Tanto el Pacto Mundial de la ONU como los Principios Rectores de las Naciones Unidas sobre Empresas y Derechos Humanos siguen el mismo modelo.

79 Véase Tully, S., "The 2000 Review of the OECD Guidelines for Multinational Enterprises", International and Comparative Law Quarterly, vol. 50(2), 2001, p. 395, quien hace referencia a la posición del BIAC en la revisión del año 2000.

80 Evans, J. y Drew, K., “The OECD Guidelines for Multinational Enterprises Responsible Business Conduct in a Global Context”, en S. F. D. I., Le pouvoir normatif de l'OCDE, París, Pedone, 2013, p. 133: "The description of the Guidelines as "voluntary" is damaging, first, because its effect is to make the Guidelines more optional, less binding, less normative. But 
Sin embargo, esa "voluntariedad" es relativa, en virtud de que los intereses conforme a los que la empresa determina su actividad son diferentes, por ejemplo, a los de las entidades o agentes gubernamentales. Al tener como principal motivación la generación de ganancias económicas, el impacto al que podría estar sujeta la reputación de una empresa con motivo de una conducta irresponsable en el ámbito de los derechos humanos o de la protección al medio ambiente es un aliciente suficientemente poderoso para alinear su comportamiento con ciertos estándares internacionales de conducta empresarial responsable. ${ }^{81}$ Por ello, el riesgo al que estarían sujetas las empresas por negarse a participar en las instancias de los Puntos de Contacto Nacional, o bien por ser identificadas como entidades que violan los derechos humanos, al trasladarse a la lógica económica, es exponencial, ${ }^{82}$ independientemente de los riesgos jurídicos a los que podrían enfrentarse en el contexto del incumplimiento de estándares nacionales que usualmente son obligatorios. Por ello, como fue mencionado por el secretario general de la OCDE, Ángel Gurría, y por Herman Mulder del Punto de Contacto Nacional de los Países Bajos, en el Segundo Foro Global de la OCDE sobre Conducta Empresarial Responsable que tuvo lugar en junio de 2014, las empresas multinacionales tienen un interés específico por evitar situaciones en que tanto ellas como terceros sufran consecuencias negativas (lose-lose situations), y por consiguiente, el hecho de que las Directrices no sean legalmente obligatorias no implica que tengan un carácter meramente voluntario.

Las Directrices de la OCDE para Empresas Multinacionales son a la fecha el único instrumento multilateral adoptado con la intención de esta-

also because the "voluntary" status of the Guidelines is invoked as a reason "to do less" when governments could and should be "doing more"”.

81 Dubin, L., loc. cit., p. 114: “L'absence d'obligatoriété des Principes directeurs ne saurait par ailleurs masquer leur dimension institutionnelle... [En plus, les entreprises] s'exposent tout au plus à devoir participer à la procédure consultative organisée par les PCNs, sinon à voir leur rétivité à prendre en compte les Principes directeurs exposée à l'opprobre d'un communiqué public".

82 Véase De Schutter, O., "The Challenge of Imposing Human Rights Norms on Corporate Actors”, en De Schutter, O. (ed.), Transnational Corporations and Human Rights, Oxford, Hart, 2006, p. 9: "Under the OECD Guidelines, the only incentive for companies to comply resides in the adverse publicity they will be subjected to if they refuse to cooperate in identifying a solution to the 'specific instance' presented to an NCP". 
blecer parámetros de comportamiento responsable a las empresas. ${ }^{83} \mathrm{Si}$ bien el único elemento vinculante del mismo es el compromiso obligatorio de los Estados de promover la aplicación de tales prácticas, constituyen en la actualidad el principal marco de referencia a nivel internacional sobre conducta empresarial responsable, a la vez que son el único instrumento que contiene algún tipo de referencia a una obligación, derivada de un acuerdo intergubernamental, relativa a la conducta de las empresas. Las Directrices se inscriben en la circunferencia que representa el área de la responsabilidad social empresarial o corporativa, misma que busca generar contribuciones positivas adicionales e independientes de los marcos jurídicos, internacionales o domésticos, que pudieran ser aplicables a las empresas transnacionales. De esta forma, la mayor parte del contenido de las Directrices se encuentra constituido por recomendaciones a las empresas sin sanciones jurídicas derivadas del derecho internacional, que buscan contribuir a la adopción generalizada de buenas prácticas en el contexto de la inversión internacional y las empresas multinacionales.

El capítulo sobre derechos humanos que se incluyó en la revisión de 2011 de las Directrices podría ser considerado como uno de los puntos de este instrumento donde la perspectiva pueda tal vez ir más allá del concepto de responsabilidad social, circunscribiéndose en una perspectiva por lo menos parcialmente jurídica, al estar fundamentado en el respeto a los derechos humanos internacionalmente reconocidos. ${ }^{84} \mathrm{Al}$ estar tales prerrogativas constituidas en diferentes tratados internacionales, de observancia obligatoria para los Estados parte, así como en declaraciones internacionales de derechos humanos con reconocimiento universal, un componente jurídico se inscribe en este instrumento de la OCDE en relación con la responsabilidad de las empresas de respetar los derechos humanos, que si bien no está claramente delimitada en términos jurídicos, ha sido interpretada como una responsabilidad independiente al deber de los Estados bajo el derecho internacional de proteger las prerrogativas fundamentales del ser humano.

83 Kothari, G., loc. cit., p. 101: "Les Principes directeurs demeurent à l'heure actuelle le seul code de conduite exhaustif adopté au niveau multilatéral, que les gouvernements se sont engagés à promouvoir. Ils restent le standard de référence en matière de responsabilité sociale des entreprises...”.

84 Véase Deva, S., op. cit., p. 85: "The Guidelines remain voluntary, but now they acknowledge that adhering states (if not MNCs) are obliged to implement them and that some matters covered in the Guidelines may be binding under national or international laws". 


\section{Sobre los Puntos de CONTACTO NaCiOnal y Su Misión COMO INSTANCIA DE SOLUCIÓN DE CONTROVERSIAS ${ }^{85}$}

Los Puntos de Contacto Nacional (PCN) son las instancias a partir de las cuales la OCDE determinó dar seguimiento puntual a la implementación de las Directrices para Empresas Multinacionales, permitiendo que al surgir controversias respecto al respeto o adecuada implementación de las mismas, existiera un mecanismo ante el cual acudir. ${ }^{86}$

Si bien algunas de las referencias doctrinales sobre este mecanismo señalan que su aparición tuvo lugar en el año $2000,{ }^{87}$ lo cierto es que han existido desde la revisión de las Directrices en el año 1984, ${ }^{88}$ aunque comenzaron a tener mayor relevancia a partir de la revisión de 1991. Así, en la enmienda de la Segunda Revisión de la Decisión del Consejo en 1991, se

85 La presente sección se enfocará casi exclusivamente al procedimiento de las instancias específicas, aunque muy breves referencias se harán a la labor del Comité de Inversiones como órgano de clarificación. Debe señalarse que varios países que no son miembros de la OCDE se han adherido a la implementación de la Declaración sobre Inversión Internacional y Empresas Multinacionales, incluyendo las Directrices para Empresas Multinacionales y los Puntos de Contacto Nacional. De esta forma, en la actualidad existen 46 adherentes, de los cuales 12 países (Argentina, Brasil, Colombia, Costa Rica, Egipto, Jordán, Latvia, Lituania, Marruecos, Perú, Rumania y Túnez) no son miembros de la OCDE, y 34 sí lo son. Sobre este tema, véase Aktypis, S., “Les Points de contact nationaux de l'O.C.D.E.”, en Decaux, E. (dir.), La responsabilité des entreprises multinationales en matière de droits de l'homme, Bruselas, Bruylant, 2010, pp. 185-202.

86 Véase Karl, J., loc. cit., p. 93: “The National Contact Points (typically a government office in a Member country) serve to gather information on experience with the Guidelines, to promote them, to handle enquiries, discuss matters related to the Guidelines and assist in solving problems which may arise between business and labour in matters covered by the Guidelines”; así como Jägers, N., op. cit., p. 106.

87 Por ejemplo, McBeth, A. \& Nolan, J., loc. cit., p. 189, y Kothari, G., loc. cit., p. 101.

88 OCDE, Second Revised Decision of the Council on the Guidelines for Multinational Enterprises (17 de mayo de 1984): "Recognising the desirability of setting forth procedures by which consultations may take place on matters related to these Guidelines... DECIDES: 1. Member Governments shall set up National Contact Points for undertaking promotional activities, handling enquiries and for discussions with the parties concerned on all matters related to the Guidelines so that they can contribute to the solution of problems which may arise in this connection”. Sobre la revisión de 1984, véase Rojot, J., “The 1984 Revision of the OECD Guidelines for Multinational Enterprises”, British Journal of Industrial Relations, vol. 3 (3), 1985. 
determinó establecer los Puntos de Contacto Nacional, que tendrían como función dar a conocer las Directrices, recibir instancias específicas (quejas) y dar orientación a las partes respecto a asuntos relativos a las Directrices. ${ }^{89}$ De la misma forma, se dispuso que los PCN de los distintos países miembros de la OCDE y demás adherentes a las Directrices podrían cooperar en caso necesario, ${ }^{90}$ estableciendo la atribución del Comité sobre Inversión Internacional y Empresas Multinacionales para actuar como intérprete de las Directrices. ${ }^{91}$ Una de las principales y más controversiales características de este instrumento fue la limitada legitimidad para presentar una instancia por un incumplimiento de alguna disposición de las Directrices, puesto que solo tenían tal capacidad los Estados miembros y las organizaciones sindicales y empresariales, a través de BIAC y TUAC. ${ }^{92}$

La revisión del año 2000 trajo consigo varios cambios sustantivos en el contenido de las Directrices — discutidos supra-y otro par en el procedimiento a seguir por los Puntos de Contacto Nacional. Al reformular la estructura de la Decisión del Consejo, se determinó incluir una guía procedimental para facilitar la comprensión del funcionamiento de los Puntos de Contacto Nacional, en la que se establecieron la mayor parte de los detalles a este respecto. La Guía de procedimiento del año 2000 estableció la legitimidad de las organizaciones no gubernamentales —además de confirmar la ya existente para organizaciones empresariales y de trabajadores- para presentar instancias específicas, así como para participar en los demás procedimientos de consulta existentes bajo la función de los Puntos de Contacto Nacional..$^{93} \mathrm{Al}$ permitir que las ONG participaran en el procedimiento, el cambio de funcionamiento fue relevante, puesto que facilitó el apoyo de estas organizaciones en la defensa de los derechos contenidos

89 OCDE, The Guidelines for Multinational Enterprises: Second Revised Decision of the Council (junio de 1991), §1.

90 Ibidem, $\$ 2$.

91 Ibidem, $\$ 3$.

92 Karl, J., loc. cit., p. 93.

93 OCDE, Guidelines for Multinational Enterprises: Procedural Guidance (27 de junio de 2000), §I.A, B.2, B.3.b), y C.2.a). Jägers, N., op. cit., p. 108: "Moreover, some adjustments have been made to the complaint procedure. Besides the business community and employee's organisations, other interested parties such as NGOs are now also allowed to file a complaint with a NCP”. 
en ese momento en las Directrices, incluyendo las breves referencias a los derechos humanos.

El segundo cambio relevante que hubo en el procedimiento de los Puntos de Contacto Nacional fue en torno a los resultados de una instancia específica, los cuales debían anunciarse en un comunicado público en caso de ser infructuosos. En el procedimiento existente bajo el régimen de las Directrices de 1991, no existían referencias expresas sobre el procedimiento a seguir, existiendo únicamente la indicación de que el Comité sobre Inversión Internacional y Empresas Multinacionales no haría conclusiones sobre la conducta de empresas individuales, ${ }^{94}$ lo cual podría tener un significado especialmente amplio y utilizarse en los procedimientos de consulta, de clarificación y de instancias específicas por igual. Sin embargo, a pesar de no estar incluido en las secciones relativas a los PCN incluidas en la Decisión del Consejo del año 2000, la Guía sobre procedimiento definió de manera clara los diferentes momentos del procedimiento de las instancias específicas. ${ }^{95}$

De tal manera, se definió que las instancias específicas contarían con tres etapas. En primer lugar, el Punto de Contacto Nacional debía determinar, a través de una evaluación inicial, si la instancia era susceptible de proceder o si debía rechazarse, con base en los alegatos presentados, lo cual debía ser comunicado a las partes. ${ }^{96}$ De proceder, el Punto de Contacto Nacional debía ofrecer sus buenos oficios y procedimientos de consulta, mediación o conciliación, para tratar de resolver la controversia, además de consultar a las instancias pertinentes — como los PCN de otros países, el Comité de Inversiones de la OCDE en caso de duda sobre la interpretación de las Directrices, las autoridades nacionales correspondientes o los expertos que se estimaran adecuados_-. ${ }^{97}$

Una vez habiendo realizado los procedimientos de consulta y utilizado sus buenos oficios para intentar solucionar la instancia, el Punto de Contacto Nacional debía emitir un comunicado y hacer las recomendaciones que estimara pertinentes de no llegarse a un acuerdo entre las partes sobre

94 OCDE, The Guidelines for Multinational Enterprises: Second Revised Decision of the Council (junio de 1991), §6.

95 OCDE, Guidelines for Multinational Enterprises: Procedural Guidance (27 de junio de 2000), §I.C.

\footnotetext{
96 Ibidem, I.C. 1.

97 Ibidem, I.C.2.
} 
las cuestiones que dieron origen a la instancia, ${ }^{98} \sin$ hacer referencia a otras consecuencias derivadas del procedimiento ni a otras acciones que el PCN debía tomar para comunicar los resultados del mismo, limitando con ello la publicidad de los procedimientos que supervisara. De la misma forma, salvo acuerdo de las partes en el procedimiento, la confidencialidad respecto a su identificación debía mantenerse, lo cual no mejoraba las probabilidades de dotar de mayor efectividad al procedimiento. ${ }^{99}$

La última revisión hecha a las Directrices de la OCDE para Empresas Multinacionales, en 2011, introdujo más cambios para intentar hacer más eficaz el procedimiento de las instancias específicas ante los Puntos de Contacto Nacional, mismos que se incluyeron en la Guía de procedimiento. Una de las principales modificaciones a las Directrices fue el hecho de eliminar el requerimiento de un vínculo de inversión que los PCN requerían para admitir una instancia; este requerimiento tendía a ser un obstáculo para que se examinaran los alegatos de incumplimiento de las Directrices en la cadena de suministro, ${ }^{100}$ a pesar de que esta recomendación se encontraba

98 Ibidem, I.C.3. Véase también De Schutter, O., "The Accountability of Multinationals for Human Rights Violations in European Law”, en Alston, P. (ed.), Non-State Actors and Human Rights, Oxford, Oxford University Press, 2006, p. 306: "However, the 2000 revision of the supervisory mechanism of the Guidelines may hold certain promise for the future. The confidential character of the proceedings before the NCP and the CIME, which previously in fact excluded pressure to comply by consumers, is not absolute anymore; and the locus standi of NGOs before the NCPs has been improved.”; Jägers, N., op. cit., pp. 108 y 109: "If the parties involved do not reach an agreement with regard to the dispute, the NCP is required to issue a statement... In its statement the NCP can decide to make the results of the proceedings public... Consequently, at the national level the naming of specific corporations might occur", y Deva, S., op. cit., p. 82.

99 Para una opinión crítica sobre las cuestiones de transparencia y confidencialidad en las instancias ante los PCN, véase Tully, S., "The 2000 Review of the OECD Guidelines for Multinational Enterprises”, International and Comparative Law Quarterly, vol. 50 (2), 2001, p. 401: "Although making the implementation of the Guidelines more explicit undoubtedly renders NCPs more transparent, this need not improve performance. Transparency is clearly limited to providing greater guidance to States and to unify the inconsistent efforts of government departments. Consequently, confidentiality clearly has the potential to override the transparency objective with resulting detriment to NCP credibility”. Véase igualmente Deva, S., op. cit., p. 84: "The OECD's procedure and usual practice of maintaining confidentiality of proceedings and the resulting reluctance to reveal the identity of an enterprise involved in a dispute make the matter worse, as there remains no scope for invoking 'social sanctions' against an MNC that infringes the Guidelines".

100 Ruggie, J.G., op. cit., pp. 174 y 175. 
en el instrumento de la OCDE mucho antes de la revisión del año 2000. Asimismo, se establecieron criterios de operación que deben ser observados por todos los PCN, los cuales deberán resolver las instancias específicas en un tiempo aproximado de 12 meses a partir de la fecha de recepción del procedimiento, de manera imparcial, previsible, equitativa y compatible con las Directrices, ${ }^{101}$ a fin de garantizar una "equivalencia funcional" entre los diferentes Puntos de Contacto Nacional, ${ }^{102}$ buscando con ello "normalizar" su funcionamiento a través de los distintos países.

Una de las mejoras sustanciales en el procedimiento de los PCN se reflejó en torno a la conclusión de la instancia, donde a diferencia del procedimiento anterior, se pretendió dar mayor énfasis a la transparencia. De esta forma, los Puntos de Contacto Nacional tienen en la actualidad la obligación de emitir un comunicado, en caso de que no se justifique un examen detallado de la instancia presentada, indicando los motivos por los cuales se haya tomado esa decisión; ${ }^{103}$ emitirán un informe cuando las partes lleguen a un acuerdo respecto de las cuestiones planteadas como incumplimiento, donde por lo menos se informarán las cuestiones analizadas, los procedimientos del PCN para auxiliar a las partes, y la fecha en que se emita el acuerdo, aunque el contenido del mismo quedará sujeto al consentimiento de las partes, ${ }^{104} \mathrm{o}$ bien, un comunicado cuando no se lograre un consenso entre las partes o cuando una de ellas se negare a participar en los procedimientos, teniendo la obligación de formular recomendaciones para la adecuada implementación de las Directrices, y estando facultado para indicar las razones por las que el acuerdo entre las partes no fue factible. ${ }^{105}$

101 OCDE, Directrices para Empresas Multinacionales: Guía de procedimiento (25 de mayo de 2011), §I.C.

102 OCDE, Comentario sobre los procedimientos de implementación de las Líneas Directrices de la OCDE para Empresas Multinacionales, 2011, §I.9.

103 OCDE, Directrices para Empresas Multinacionales: Guía de procedimiento, 2011, §I.C.3.a).

104 Ibidem, §I.C.3.b).

105 Ibidem, §I.C.3.c). Cfr. Černič, J. L., Human Rights Law and Business: Corporate Responsibility for Fundamental Human Rights, Groningen, Europa Law Publishing, 2010, p. 197. Černič hacía referencia a esto previo a la revisión de las Directrices en 2011, así como una crítica general al sistema de los PCN previo a su última revisión: "It appears reasonable that if mediation attempts between parties are not successful, the NCP should determine whether the allegations are true or false following a fact-finding inquiry, where both parties can contribute to achieving consensus. Each party should be given the opportunity to state and defend their 
El potencial que engloba esta modificación en el procedimiento de las instancias específicas ante los Puntos de Contacto Nacional para contribuir a un mayor respeto de los derechos humanos por parte de las empresas multinacionales es aún incierto, pero existen altas probabilidades de que fomente el aprendizaje mutuo entre los diferentes PCN, así como un mayor conocimiento del público general respecto a este mecanismo y a las Directrices. ${ }^{106}$ Así, el desarrollo de la "jurisprudencia" resultante de los comunicados e informes que emitan los Puntos de Contacto Nacional en los diferentes países pueden generar una cristalización de criterios uniformes, que permita construir una base sólida de interpretación respecto a las Directrices para Empresas Multinacionales. ${ }^{107}$

Dos críticas constantes aparecen, sin embargo, en este contexto. La primera, que ya ha sido mencionada anteriormente, es la disparidad en torno a los criterios de interpretación de las Directrices para Empresas Multinacionales por parte de los Puntos de Contacto Nacional, mientras que la segunda es en relación con su actuación. En esta última, a pesar del establecimiento de criterios y estándares para intentar guiar los procedimientos de los PCN en torno a la admisión de instancias específicas, aparentemente continúa existiendo una importante cantidad de criterios heterogéneos. ${ }^{108}$ Desde luego, la existencia de un pobre nivel de comprensión respecto al

case to the NCP in written submissions and at meetings convened between the parties". Cfr. también con Deva, S., op. cit., p. 88: "Nor have the NCPs been obliged to make a determination, if the mediation fails, as to the merits of the complaint in relation to the alleged breach of the Guidelines. This is the minimum that the NCPs should do if they lack enforcement powers, so that social sanctions can come into play”.

106 Ruggie, J. G., op. cit., p. 175.

107 Ibidem, p. 175: "Through such NCP deliberations, the functional equivalent of «jurisprudence» in human rights cases will emerge across the forty-two adhering governments official interpretations of the meaning of the OECD Guidelines' requirements for the corporate responsibility to respect human rights in specific contexts, fleshing out the higher-level guidance the GPs provide”. Cfr. Černič, J. L., Human Rights Law and Business: Corporate Responsibility for Fundamental Human Rights, Groningen, Europa Law Publishing, 2010, p. 193: "It is notable that NCPs' jurisprudence is inconclusive in a strict sense, as NCPs make decisions very differently and they lack transparency in the decision-making process".

108 Robinson, S., "International Obligations, State Responsibility and Judicial Review Under the OECD Guidelines for Multinational Enterprises Regime”, Utrecht Journal of International \& European Law, vol. 30 (78), 2014, p. 72: "Furthermore, the handling of specific instances is particularly problematic, and the majority of NCPs have weak records in this regard. There are no set, uniform procedures that NCPs must follow when receiving and 
criterio inicial de admisión de las instancias _ tal vez derivado de una falta de mayor especificidad de las Directrices_- genera consecuencias potencialmente negativas para el resto del procedimiento, y en especial para los criterios de interpretación de las Directrices. Aunque también es cierto que las circunstancias de cada instancia podrían hacer variar la interpretación de las Directrices por los PCN, la aparente inexistencia de un aprendizaje general acumulado respecto a la interpretación oficial de las disposiciones contenidas en este instrumento podría constituir una limitante estructural que inhibe el progreso de este mecanismo.

Uno de los principales problemas que existe con el mecanismo de la OCDE — pero que es propio de la naturaleza del derecho internacional_es la falta de medios para garantizar la participación activa o cumplimiento de las recomendaciones hechas a los sujetos a quienes están dirigidas las Directrices, en este caso las empresas multinacionales. ${ }^{109} \mathrm{Al}$ tener un carácter voluntario, las Directrices para Empresas Multinacionales son incapaces de asegurar que tales recomendaciones van a ser efectivamente puestas en práctica por las empresas, o bien, que los resultados y llamados que hagan los Puntos de Contacto Nacional a empresas para participar en las instancias específicas por supuestas violaciones a las Directrices tengan algún tipo de efecto. Esta situación constituye un obstáculo para la plena efectividad de las Directrices, limitando su eficacia, normalmente circunscrita a la voluntad de los Estados para garantizar la aplicación de normas internacionales en su jurisdicción. ${ }^{110}$ En este sentido, la única solución que existiría para lograr una mayor efectividad y un mayor apego a estas normas por parte de las empresas _ además de la transformación de las Directrices en normas jurídicas de derecho internacional directamente aplicables a ellas, lo cual parece ser una posibilidad remota_-, sería que los Estados miem-

considering a specific instance complaint. Consequently, the procedures that NCPs have established to handle complaints vary from NCP to NCP”.

109 Evans, J. y Drew, K., loc. cit., p. 130: “Despite their significant potential the often poor performance of NCPs together with the refusal of some companies to participate in the NCP process have weakened the normative power of the Guidelines".

110 McBeth, A. y Nolan, J., loc. cit., p. 190: "The Guidelines were initially revolutionary because they explicitly delineated corporate obligations with respect to protecting human rights. However, their impact has been diluted because their application is subject to limitations. Decisions cannot be enforced directly against corporations and the power to compel behavioural change depends upon the political will and ability of national governments". 
bros de la OCDE determinen en su legislación interna la obligación de las empresas de respetar dichos estándares internacionales y de comparecer ante los PCN correspondientes cuando éstos las requieran, ${ }^{111}$ particularmente tratándose de los Estados de donde son originarias las empresas o en donde éstas tengan su domicilio social o lugar de administración. ${ }^{112}$

Otro punto a considerar es relativo al propio procedimiento realizado por los Puntos de Contacto Nacional, y a la inexistente posibilidad de presentar pruebas en las instancias específicas que se promuevan. Lo anterior tiene como base el carácter no adversarial de las instancias específicas, mismo que se resuelve de forma exclusiva a través de la valoración de los alegatos e información que presenten las partes involucradas en un procedimiento cuando no fuere posible una solución amistosa, o bien, como resultado de una mediación o conciliación efectiva entre los intereses de las partes. De tal manera, la única aportación realizada por las partes en una instancia específica lo constituyen los hechos alegados al presentar la instancia y al otorgar la empresa involucrada — en su caso — su respuesta a los alegatos y a los cuestionarios que pudiere realizar el Punto de Contacto Nacional respecto a su implementación de las Directrices de la OCDE para Empresas Multinacionales. ${ }^{113}$

Si en una futura revisión de las Directrices se busca potencializar la verdadera efectividad de su contenido y de sus procedimientos, uno de los principales temas a tratar será precisamente el de la participación de las empresas en las instancias específicas, y en particular la determinación de consecuencias para aquéllas empresas que rehúsen colaborar con las instancias o que ignoren las recomendaciones hechas por el Punto de Contacto Nacional correspondiente. ${ }^{114}$ El marco propuesto por la OCDE es en la

111 Sin embargo, cfr. Dubin, L., loc. cit., p. 115.

112 Véase Kothari, G., loc. cit., p. 100; Dubin, L., loc. cit., p. 126.

113 Un excelente ejemplo de la valoración realizada por un PCN (el de Noruega en este caso) puede encontrarse en: Norwegian NCP, Final Statement: ForUM v. NBIM (27 de mayo de 2013), en http: / / www.responsiblebusiness.no/files/2013/12/nbim_final.pdf(visitado por última vez el 9 de septiembre de 2014).

114 Ruggie, J.G., op. cit., pp. 175-176. Véase también Special Representative of the Secretary-General on the issue of human rights and transnational corporations and other business enterprises, Updating the Guidelines for Multinational Enterprises: Discussion Paper (30 de junio de 2010), §35, disponible en http://www.oecd.org/daf/inv/mne/45545887.pdf (Visitado por última vez el 1o. de julio de 2014). 
actualidad el único instrumento adoptado multilateralmente en torno al tema de la responsabilidad de las empresas por su impacto en la sociedad, y a pesar de no tener una naturaleza jurídica, es potencialmente útil $;^{115}$ sin embargo, para lograr obtener de él los resultados para los que fue diseñado, los Estados, por una parte, y los Puntos de Contacto Nacional, por otra, deberán asumir sus respectivas responsabilidades para garantizar que su compromiso sea mayoritariamente con la defensa de los derechos humanos y de los intereses sociales, y de menor escala con los intereses económicos de las empresas. ${ }^{116}$

\section{BREVES OBSERVACIONES RESPECTO A LA EXPERIENCIA MEXICANA Con el Punto de Contacto Nacional de la OCDE ${ }^{117}$}

La presente sección busca ilustrar, de manera breve, algunas de las características que comparten hasta la fecha las determinaciones hechas por el Punto de Contacto Nacional de México en las instancias específicas que se han presentado. Por ello, se hará una reseña concisa de las características comunes que comparten las instancias presentadas, con el objetivo de que sirvan de ejemplo a las consideraciones y argumentos expuestos en las secciones precedentes.

115 Clapham, A., op. cit., p. 202: "To be clear, there is still no procedure for legally enforcing any sort of finding against a multinational enterprise; but, the complaint mechanisms are beginning to attract more attention".

116 Ibidem, p. 211: "The prospects for success will depend in part on the attention that is given to ensuring that NCPs feel accountable beyond the business sector."; véase también Robinson, S., loc. cit., p. 80: "The OECD can and must do more to mandate a more cohesive, competent, and proactive effort by states and their NCPs when handling specific instances".

117 La información presentada en esta sección fue obtenida por medio de una solicitud de transparencia a la Secretaría de Economía del Gobierno mexicano, encargada de la administración del Punto de Contacto Nacional. Sin embargo, ésta se encuentra disponible en su totalidad en la página de internet del Comité Asesor Sindical (TUAC), en http: / / www.tuacoecdm neguidelines.org/cases. asp?organisationid $=22899 \& N C P=Y$ (visitada por última vez el 1o. de julio de 2014). Se anota que existe una disparidad importante entre la información presentada por la Secretaría de Economía y los perfiles de casos elaborados por TUAC, particularmente en cuanto a las fechas de inicio y fin de las instancias, así como respecto a su actual desarrollo. 
A la fecha, se han presentado cinco instancias específicas ante el PCN mexicano, ${ }^{118}$ de las cuales dos de ellas fueron presentadas conforme a los lineamientos establecidos por la revisión del año 2000 de las Directrices para Empresas Multinacionales, y tres más fueron presentadas tras la revisión del año 2011, existiendo a la fecha una sola Decisión. En las cinco instancias intentadas se ha alegado un incumplimiento con los estándares existentes en materia de empleo y relaciones laborales, aunque en dos de ellas, posteriores a la revisión de 2011, se han alegado igualmente violaciones a los derechos humanos, así como a las disposiciones de otros de los capítulos sustantivos de las Directrices. De las cinco instancias recibidas, el Punto de Contacto Nacional ha colaborado con sus contrapartes de otros países (en particular Alemania, Finlandia y Canadá) con motivo de los orígenes de las empresas involucradas, y dos se han tramitado de forma individual, al involucrar la participación de dos multinacionales mexicanas.

La primera instancia en que participó el Punto de Contacto Nacional de México, presentada en mayo de 2002 contra Continental AG (Continental Tire), tenía como argumento principal el cierre de una planta perteneciente a la subsidiaria (Euzkadi) de la multinacional alemana sin previo aviso a los trabajadores. El procedimiento fue inicialmente presentado ante el PCN alemán por dos ONG de ese país en representación de un sindicato mexicano, pero luego transferido al Punto de Contacto Nacional de México. A pesar de no haber utilizado sus buenos oficios, el caso se resolvió en 2005 a través de un convenio, por el que se reabrió la planta como una cooperativa en un proyecto de joint venture con inversionistas mexicanos. ${ }^{119}$

La segunda instancia que tuvo el PCN de México — que es en la única en que ha emitido una decisión - involucró al Grupo Modelo, y fue presentada en junio de 2008. La instancia fue presentada contra Industria Vidriera del Potosí, subsidiaria de la agrupación antes mencionada, con base en un

118 La información disponible en la página de internet del Comité Asesor Sindical (TUAC), sin embargo, indica que a la fecha se han presentado seis casos ante el PCN mexicano, lo cual contradice la información presentada por la Secretaría de Economía. El caso presentado contra Michelin y su subsidiaria mexicana, Uniroyal, en 2004 no ha sido reportado como concluido. Para mayor información sobre el perfil de este caso, vea TUAC, Michelin v. SNTU, S.A. de C.V., perfil disponible en http://www.tuacoecdmneguidelines.org/CaseDescription.asp?id=33 (visitada por última vez el 1o. de julio de 2014).

119 TUAC, Continental v. SNRTE, perfil disponible en http: / / www.tuacoecdmneguidelines.org/ CaseDescription.asp?id=81 (visitada por última vez el 1o. de julio de 2014). 
despido colectivo de trabajadores, lo cual sería contrario a las disposiciones de las Directrices relativas al empleo y las relaciones laborales. Tras haber consultado a las partes involucradas, a las autoridades federales en materia laboral y a la Organización Internacional del Trabajo, ante la que también se había presentado una queja, el PCN emitió su decisión inicial, en la que informó que al no detectar violaciones a las Directrices como resultado del análisis de las pruebas aportadas por las partes y autoridades, ${ }^{120} \mathrm{y}$ al haber sido resuelta en su totalidad la acción presentada ante las autoridades nacionales competentes, ${ }^{121}$ se determinó cerrar el caso. ${ }^{122}$

Una tercera instancia específica fue presentada contra América Móvil, multinacional mexicana del sector de telecomunicaciones, en septiembre de 2011, por un conjunto de organizaciones sindicales lideradas por UNI Global Union. ${ }^{123}$ En la instancia se alegaban violaciones a las disposiciones sobre políticas generales, derechos humanos, empleo y relaciones laborales, incluyendo al deber de debida diligencia en sus operaciones y de alentar a sus socios comerciales a aplicar principios de conducta empresarial responsable, con base en alegadas conductas que contravendrían las disposiciones de las Directrices en sus operaciones en El Salvador, Guatemala y Nicaragua.

120 PCN de México, Caso Industria Vidriera del Potosí, Oficio No. DGIE.09.2959 (13 de enero de 2010), p. 1: “Que este PCN considera que no existen elementos para admitir la Instancia Específica, toda vez que de las pruebas y documentación aportadas por las partes y autoridades involucradas, no se han detectado posibles violaciones a las Directrices".

121 Ibidem: "Que de acuerdo a la información obtenida por las partes y por la autoridad laboral mexicana se observa que los hechos controvertidos que se presentaron al análisis de este PCN fueron estudiados y resueltos en su totalidad por las autoridades judiciales competentes, por lo que no corresponde a este PCN pronunciarse o evaluar cuestiones que ya han sido resueltas por la autoridad competente".

122 TUAC, Grupo Modelo v. Sindicato Único de Trabajadores de la Empresa Industria Vidriera del Potosí, S.A. de C.V., perfil disponible en http://www.tuacoecdmneguidelines.org/CaseDescription. asp?id=7 (visitada por última vez el 1o. de julio de 2014).

123 Según información proporcionada por el Subdirector de Tratados para Europa y Organismos Internacionales de la Dirección General de Inversión Extranjera, dependiente de la Secretaría de Economía, se presentaron dos instancias conexas en cuanto a las partes y alegatos presentados en contra de América Móvil y sus subsidiarias centroamericanas. Sin embargo, debido a la conexidad existente en la causa y a la inexistencia de nueva información o señalamientos por la parte solicitante, el Punto de Contacto Nacional de México se apegó a la decisión emitida en junio de 2012. 
Desde luego, el carácter extraterritorial de los hechos podría presentar algunas barreras para que el PCN se hiciera de información fidedigna, aunque las Directrices, su comentario y la guía de procedimiento establecen específicamente que las Directrices son aplicables a empresas que trabajen en o desde los Estados miembros de la OCDE, y por consecuencia al caso presentado contra América Móvil. Conforme a la información provista por la Secretaría de Economía, la ausencia de elementos suficientes para llevar a cabo un análisis a profundidad condujo al cierre de la instancia desde la evaluación inicial en junio de 2012. Siendo la primera instancia presentada conforme a la última revisión de las Directrices de la OCDE para Empresas Multinacionales, el PCN de México estaría obligado a emitir un comunicado público donde se informen los motivos por los que tomó la determinación de cerrar la instancia. Sin embargo, de la información oficial de la Secretaría de Economía, complementada con el informe del caso realizado por TUAC, tal decisión no fue hecha pública por el Punto de Contacto Nacional de México, en contravención de las disposiciones de las Directrices. ${ }^{124}$

Una cuarta instancia específica fue presentada por la ONG Pro-DESC en contra de Excellon Resources Inc., empresa minera de Canadá, y sus dos subsidiarias mexicanas en mayo de 2012, ante el PCN de México en colaboración con el mecanismo en Canadá. En la instancia se alegaban violaciones a las disposiciones relativas a la revelación de información, al empleo y las relaciones laborales, a los derechos humanos y al medio ambiente en las operaciones de las subsidiarias en Durango.

Sin embargo, en noviembre de 2012, el PCN de México determinó que no podría ofrecer sus buenos oficios en el caso por diversas razones, incluyendo la existencia de procedimientos legales paralelos, la consideración de que los hechos alegados no eran concluyentes ni estaban probados, el rechazo de la empresa de participar en cualquier intento de mediación debido a la "falta de buena fe" de su contraparte, la dificultad de resolver

124 TUAC, América Móvil, S.A.B. de C.V.v. UNI Global Union et al., perfil disponible en http: //www.tuacoecdmneguidelines.org/CaseDescription.asp?id=161 (visitada por última vez el 10 . de julio de 2014). Conforme a la información publicada por TUAC, el comunicado sobre la decisión del PCN indicaría que al no ser El Salvador, Guatemala y Nicaragua miembros de la OCDE, no podrían aplicarse las Directrices para Empresas Multinacionales a las empresas centroamericanas. De ser cierto, estaría apartándose de la intención y letra de las Directrices. 
el caso a través de la mediación, y a negociaciones paralelas a nivel político de alto nivel. Por tanto, desechó la instancia a través de su comunicado de evaluación inicial, sin emitir un comunicado final ni hacer público ninguno de los documentos. ${ }^{125}$

Una última instancia específica ante el Punto de Contacto Nacional mexicano en colaboración con su contraparte de Finlandia, de septiembre de 2012, fue solicitada por el Sindicato Nacional de Trabajadores Mineros, Metalúrgicos, Siderúrgicos y Similares de la República Mexicana e IndustriAll en contra de Grupo PKC, una empresa metalúrgica de origen finlandés con actividades en el sector automotriz, por violaciones al capítulo sobre empleo y relaciones laborales de las Directrices, en particular a la representación sindical de los trabajadores y al derecho a la negociación colectiva de los trabajadores.

El PCN determinó, tras su evaluación inicial, que no podría ofrecer sus buenos oficios a las partes por la existencia de procedimientos legales paralelos, la falta de justificación y prueba de las alegaciones presentadas, y al carácter de la queja, considerando que correspondía su decisión a las autoridades laborales, y que la mediación no sería una instancia apropiada. Sin embargo, al igual que en la mayoría de los casos recibidos, el PCN no publicó un informe o comunicado final sobre el caso en donde describiera los motivos por los que determinó la improcedencia de la instancia. ${ }^{126}$

Como bien han señalado varios académicos, ${ }^{127}$ es de suma importancia que los PCN, y en particular el Punto de Contacto Nacional de México, de-

125 TUAC, Excellon Resources Inc. v. Pro-DESC, A.C., perfil disponible en http: / / www.tuacoecd mneguidelines.org/CaseDescription. asp?id=163 (visitada por última vez el 1o. de julio de 2014). Existe una traducción de la evaluación inicial hecha por el PCN de México, realizado por una Perito adscrita al Tribunal Superior de Justicia del Distrito Federal. De tal documento, se desprenden las afirmaciones hechas en el cuerpo de este artículo respecto al caso de Excellon, mismas que son reproducidas en la información presentada por la Secretaría de Economía. Un elemento positivo que se desprende de tal documento son los puntos resolutivos tercero y cuarto, donde el PCN “urge a Excellon Canada a asegurar la implementación de los principios contenidos en las Directrices en el desarrollo de sus actividades en cualquier país donde tenga operaciones”, y “urge a Excellon México a tomar cualquier acción disponible para atender los asuntos que dieron origen a la solicitud de la Instancia Específica”.

126 TUAC, PKC Group v. SNTMMSSRM et al., perfil disponible en http://www.tuacoecdm neguidelines.org/CaseDescription.asp?id=167 (visitada por última vez el 1o. de julio de 2014).

127 Karl, J., loc. cit., pp. 94 y 95: "When Guidelines issues arise in specific cases, the onus of attempting a settlement is particularly on the National Contact Point; hence, the effectiveness 
pendiente de la Secretaría de Economía, se conduzca con apego a los lineamientos de procedimiento establecidos en las Directrices de la OCDE para Empresas Multinacionales, y que garantice una actuación imparcial, puesto que de dicho mecanismo dependerá el éxito o fracaso en una mejor y más amplia implementación de las Directrices. Como ya se pudo experimentar en el caso mexicano, los mecanismos de implementación de las Directrices de la OCDE para Empresas Multinacionales ya no solo tratan cuestiones relativas a las actividades en México de empresas multinacionales extranjeras, sino también las acciones de las multinacionales mexicanas que tienen operaciones en el exterior. Por tanto, es necesario que las instancias correspondientes actúen de forma adecuada y con apego a sus mandatos, a fin de contribuir a una mayor difusión de conductas empresariales responsables y buenas prácticas que permitan al país contribuir al desarrollo y respeto de los derechos humanos y otras prerrogativas no solo en México, sino en el extranjero, y de contribuir recíprocamente al desarrollo de una cultura empresarial en el ámbito de los derechos humanos.

\section{CONCLUSIONES: ¿QUÉ APORTAN LAS DIRECTRICES DE LA OCDE A LA CUESTIÓN DE LA RESPONSABILIDAD DE LAS EMPRESAS EN EL ÁMBITO DE LOS DERECHOS HUMANOS?}

Las Directrices de la OCDE para Empresas Multinacionales, a través de su revisión de 2011, contribuyeron a la convergencia de estándares a nivel internacional en materia de derechos humanos. Si bien son un instrumento de responsabilidad social corporativa o empresarial, que tiende a sugerir a las empresas la adopción voluntaria de conductas responsables y respetuosas de la sociedad en que operan sin aparentes consecuencias jurídicas, el capítulo cuarto de las Directrices, sobre derechos humanos, es un elemento que potencialmente puede cambiar ese carácter "voluntario".

of the Guidelines depends to a large degree on that of the Contact Points". Véase también Steinhardt, R. G., "Corporate Responsibility and the International Law of Human Rights: The New Lex Mercatoria”, en Alston, P. (ed.), Non-State Actors and Human Rights, Oxford, Oxford University Press, 2006, p. 210: "Implementation necessarily rests on the will of governments through their National Contact Points, as specified in the Guidelines...”. 
Al equipararse los estándares de la OCDE con los Principios Rectores de la ONU sobre empresas y derechos humanos, las principales diferencias que resaltan son el instrumento de implementación de las Directrices, a través de los Puntos de Contacto Nacional, así como el hecho de ser el único instrumento intergubernamental adoptado en la materia a nivel internacional. En principio, el compromiso de los Estados miembros de la OCDE, y de aquellos adherentes a las Directrices, de difundir este instrumento y de establecer mecanismos domésticos para dirimir las controversias que de su aplicación resulten, son elementos necesarios para lograr el desarrollo cultural que la OCDE busca en las actividades de las empresas. Sin embargo, el tono que aún mantiene el texto de las Directrices, a pesar de su reformulación y de añadir casi de forma íntegra los Principios Rectores de las Naciones Unidas, aparenta jugar en su contra, específicamente al continuar señalando, con el ferviente apoyo de varios Estados y de BIAC, que su naturaleza y adopción por las empresas es estrictamente voluntario.

Otro aspecto importante a considerar es el trabajo que realizan los Puntos de Contacto Nacional. Durante el Segundo Foro Global de la OCDE sobre Conducta Empresarial Responsable, que tuvo lugar a finales de junio de 2014, se hizo énfasis en que el éxito o fracaso de las Directrices alrededor del mundo dependen casi exclusivamente del trabajo realizado por los mecanismos de implementación, lo cual, desde luego, en muchas instancias se traduce a la voluntad de los gobiernos. Como señaló Alexandra Guáqueta, del Grupo de Trabajo de las Naciones Unidas sobre Empresas y Derechos Humanos, la falta de capacidad —en términos económicos o de recursos humanos - para implementar adecuadamente el sistema de los Puntos de Contacto Nacional es utilizada por algunos Estados como una excusa para esconder una verdadera falta de compromiso y voluntad política. Mucho trabajo deberá hacerse en este sentido, si en realidad se desea contar con un ecosistema funcional de conducta empresarial responsable. El primer paso, desde luego, está en que los Puntos de Contacto Nacional cumplan su papel conforme al texto vigente de las Directrices, y que además de sus buenos oficios, emitan sus evaluaciones y recomendaciones en caso de falta de voluntad de la empresa para participar en la solución de controversias.

A nivel institucional, la Organización para la Cooperación y el Desarrollo Económicos también tienen un papel importante que jugar, y algunas decisiones, por pequeñas que puedan resultar, tendrían el potencial de au- 
mentar la comprensión y desarrollo de sus acciones en favor de la protección de los derechos humanos. En esta materia, donde nuevos retos para la protección de los derechos humanos ante las actividades empresariales surgen de forma constante y continua, sería prudente que exista una cooperación institucional formal entre el Grupo de Trabajo de la OCDE sobre Conducta Empresarial Responsable, y el Grupo de Trabajo de las Naciones Unidas sobre Empresas y Derechos Humanos.

El último, como intérprete de los Principios Rectores, tendría una capacidad especializada para aconsejar al primero sobre los distintos retos que observe en el área, así como sobre la interpretación del capítulo cuarto de las Directrices de la OCDE para Empresas Multinacionales, al estar basado en el instrumento de la ONU. Esta interacción bidireccional, en donde el Grupo de Trabajo de la OCDE también podría informar a su contraparte de la ONU sobre instancias específicas que contengan elementos novedosos en el ámbito y que podrían servir para el desarrollo de líneas directrices, sería benéfica para la interpretación que realice el Comité de Inversión de la OCDE sobre las Directrices para Empresas Multinacionales.

En una era en que hay un fuerte interés en el impacto que los diferentes actores de la sociedad producen a nivel internacional, una contribución positiva y un comportamiento responsable de parte de las empresas, multinacionales o locales, es la expectativa común a nivel internacional. Las empresas pueden aún mover su capital y actividades a zonas de débil regulación por parte de los Estados, a fin de mantener una ventaja competitiva; sin embargo, para mantener su reputación y el valor de sus marcas - hoy más que nunca sujetas a la regulación social ejercida por los consumidores e inversionistas - , podría resultar una mejor decisión contribuir a mejorar las condiciones en las zonas donde operen, a fin de participar en la generación de un entorno en donde un desarrollo sostenible y responsable sea una verdadera posibilidad.

\section{BIBLIOGRAFÍA}

AdDo, M. K., "The Reality of the United Nations Guiding Principles on Business and Human Rights”, Human Rights Law Review, vol. 14 (1), 2014. 
AKTYPIS, S., “Les Points de contact nationaux de l’O.C.D.E.”, en DECAuX, E. (dir.), La responsabilité des entreprises multinationales en matière de droits de l'homme, Bruselas, Bruylant, 2010.

Alvarez, J. E., The Public International Law Regime Governing International Investment, Leiden, Brill, 2011.

CANTÚ RiverA, H. F., "Empresas y derechos humanos: ¿hacia una regulación jurídica efectiva, o el mantenimiento del status quo?”, Anuario Mexicano de Derecho Internacional, vol. XIII, 2013.

-, "Evaluando los Principios Rectores sobre Empresas y Derechos Humanos a dos años de su adopción”, Revista Internacional de Derechos Humanos, núm. 3, 2013.

ČERniČ, J. L., Human Rights Law and Business: Corporate Responsibility for Fundamental Human Rights, Groningen, Europa Law Publishing, 2010.

, "The 2011 Update of the OECD Guidelines for Multinational Enterprises", American Society of International Law Insights, vol. 16(4), 2012.

Chaumette, A. L., "La responsabilité de protéger, interrogations sémantiques", en Chaumette, A. L. y Thouvenin, J. M., La responsabilité de protéger, dix ans après, París, Pedone, 2013.

Clapham, A., Human Rights Obligations of Non-State Actors, Oxford, Oxford University Press, 2006.

De SchutTer, O., "The Challenge of Imposing Human Rights Norms on Corporate Actors", en DE SCHUTTER, O. (ed.), Transnational Corporations and Human Rights, Oxford, Hart, 2006.

, "The Accountability of Multinationals for Human Rights Violations in European Law", en Alston, P. (ed.), Non-State Actors and Human Rights, Oxford, Oxford University Press, 2006.

- et al., Human Rights Due Diligence: The Role of States, ICAR/ ECCJ, 2012.

DeCAuX, E., 'Le projet de l'ONU sur la responsabilité des entreprises transnationales', in Daugareilh, I. (ed.), Responsabilité sociale de l'entreprise transnationale et globalisation de l'économie, Bruselas, Bruylant, 2010.

DEVA, S., Regulating Corporate Human Rights Violations: Humanizing Business, Londres, Routledge, 2012. 
Deva, S. y Bilchitz, D. (eds.), Human Rights Obligations of Business: Beyond the Corporate Responsibility to Respect?, Cambridge, Cambridge University Press, 2013.

DuBIN, L., "L'élaboration des principes à l'intention des entreprises multinationales par l'OCDE ou comment globaliser la régulation du comportement d'un acteur global?", en S.F.D.I., Le pouvoir normatif de l'OCDE, París, Pedone, 2013.

Evans, J. y DrEw, K., “The OECD Guidelines for Multinational Enterprises Responsible Business Conduct in a Global Context”, en S. F. D. I., Le pouvoir normatif de l'OCDE, París, Pedone, 2013.

FAJNZYLBER, F. y MARTÍNEZ TARRAGÓ, T., Las empresas transnacionales: Expansión a nivel mundial y proyección en la industria mexicana, México, FCE, 1974.

FEENEY, P., "Empresas y derechos humanos: La lucha por la rendición de cuentas en la ONU y el rumbo futuro de la agenda de incidencia”, SURRevista Internacional de Derechos Humanos, vol. 6, núm. 11, 2009.

Harrison, J., "Human Rights Measurement: Reflections on the Current Practice and Future Potential of Human Rights Impact Assessment", Journal of Human Rights Practice, vol. 3 (2), 2011.

-, "Establishing a Meaningful Human Rights Due Diligence Process for Corporations: Learning from Experience of Human Rights Impact Assessment”, Impact Assessment and Project Appraisal, vol. 31 (2), 2013.

Herdegen, M., Principles of International Economic Law, Oxford, Oxford University Press, 2013.

JäGERS, N., Corporate Human Rights Obligations: in Search of Accountability, Antwerp, Intersentia, 2002.

KARL, J., "The OECD Guidelines for Multinational Enterprises”, en ADDO, M. K. (ed.), Human Rights Standards and the Responsibility of Transnational Corporations, La Haya, Kluwer Law International, 1999.

Kauzlarich, R. D., "The Review of the 1976 OECD Declaration on International Investment and Multinational Enterprises", The American University Law Review, vol. 30, 1981.

Keller, H., "Corporate Codes of Conduct and their Implementation: The Question of Legitimacy”, en WOLfrum, R. y RÖBEN, V. (eds.), Legitimacy in International Law, Berlín, Springer, 2008. 
KOTHARI, G., "L'élaboration des principes et standards à l'intention des entreprises: L'approche innovante de l'OCDE”, en S.F.D.I., Le pouvoir normatif de l'OCDE, París, Pedone, 2013.

Lambooy, T., "Corporate Due Diligence as a Tool to Respect Human Rights”, Netherlands Quarterly of Human Rights, vol. 28 (3), 2010.

Mares, R. (ed.), The UN Guiding Principles on Business and Human Rights: Foundations and Implementation, Leiden, Martinus Nijhoff, 2012.

, "Responsibility to Respect: Why the Core Company Should Act When Affiliates Infringe Human Rights", en Mares, R. (ed.), The UN Guiding Principles on Business and Human Rights: Foundations and Implementation, Leiden, Martinus Nijhoff, 2012.

Martín-Ortega, O., "Human Rights Due Diligence for Corporations: From Voluntary Standards to Hard Law at Last?", Netherlands Quarterly of Human Rights, vol. 31(4), 2013.

McBeth, A. y Nolan, J., "The International Protection of Human Rights and Fundamental Freedoms", en Tully, S. (ed.), International Corporate Legal Responsibility, Alphen aan den Rijn, Kluwer Law International, 2012.

Morgera, E., Corporate Accountability in International Environmental Law, Oxford, Oxford University Press, 2009.

Muchlinski, P. T., Multinational Enterprises \& The Law, 2a. ed., Oxford, Oxford University Press, 2007.

Newcombe, A. y Paradell, L., Law and Practice of Investment Treaties, Alphen aan den Rijn, Kluwer Law International, 2009.

Nieuwenkamp, R., "Cut and Run, or Stay and Help?", Ethical Corporation, 2014.

Rasche, A., "The United Nations and TNCs: How the UN Global Compact Has Changed The Debate", en Lawrence, J. y BeAmish, P. (eds.), Globally Responsible Leadership: Managing According to the UN Global Compact, Thousand Oaks, Sage, 2013.

ReInISCH, A., Recent Developments in International Investment Law, París, Pedone, 2009.

Robinson, S., "International Obligations, State Responsibility and Judicial Review Under the OECD Guidelines for Multinational Enterprises Regime”, Utrecht Journal of International \& European Law, vol. 30(78), 2014. 
ROJOT, J., “The 1984 Revision of the OECD Guidelines for Multinational Enterprises", British Journal of Industrial Relations, vol. 3(3), 1985.

RuBIN, S. J., "Transnational Corporations and International Codes of Conduct. A Study of the Relationship Between International Legal Cooperation and Economic Development", American University International Law Review, vol. 10:4, 1995.

Ruggie, J. G., Just Business: Multinational Corporations and Human Rights, Nueva York, W.W. Norton, 2013.

SEIDL-Hohenveldern, I., "International Economic Law: General Course on Punlic International Law", Collected Courses of the Hague Academy of International Law, vol. 198, Leiden, Martinus Nijhoff, 1986.

Sepúlveda Amor, B. et al., Las empresas transnacionales en México, México, El Colegio de México, 1974.

SHAN, W., "Towards a Balanced Liberal Investment Regime: General Report on the Protection of Foreign Investment”, ICSID Review-Foreign Investment Law Journal, vol. 25:2, 2010.

SteinhardT, R. G., "Corporate Responsibility and the International Law of Human Rights: The New Lex Mercatoria”, en Alston, P. (ed.), NonState Actors and Human Rights, Oxford, Oxford University Press, 2006.

Tully, S., "The 2000 Review of the OECD Guidelines for Multinational Enterprises”, International and Comparative Law Quarterly, vol. 50(2), 2001.

, "Introduction", en Tully, S. (ed.), International Corporate Legal Responsibility, Alphen aan den Rijn, Kluwer Law International, 2012.

Zamora, F. J. et al. (eds.), La responsabilidad de las multinacionales por violaciones de derechos humanos, Alcalá de Henares, Universidad de Alcalá-Defensor del Pueblo, 2013. 